Renata Soares Marangoni

Níveis de cálcio e fósforo disponível para frangos de corte alimentados com dietas contendo doses crescentes de fitase

Pirassununga 


\section{Níveis de cálcio e fósforo disponível para frangos de corte alimentados com dietas contendo doses crescentes de fitase}

Dissertação apresentada ao Programa de Pós- Graduação em Nutrição e Produção Animal da Faculdade de Medicina Veterinária e Zootecnia da Universidade de São Paulo para a obtenção do título de Mestre em Ciências

Departamento:

Nutrição e Produção Animal

Área de concentração:

Nutrição e Produção Animal

Orientador:

Prof. Dra. Cristiane Soares da Silva de Araújo

Pirassununga 
Autorizo a reproduçäo parcial ou total desta obra, para fins acadêmicos, desde que citada a fonte.

DADOS INTERNACIONAIS DE CATALOGAÇÃO NA PUBLICAÇÃO

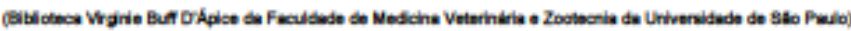

\begin{tabular}{|c|c|}
\hline $\begin{array}{l}\text { T. } 3515 \\
\text { FMVZ }\end{array}$ & 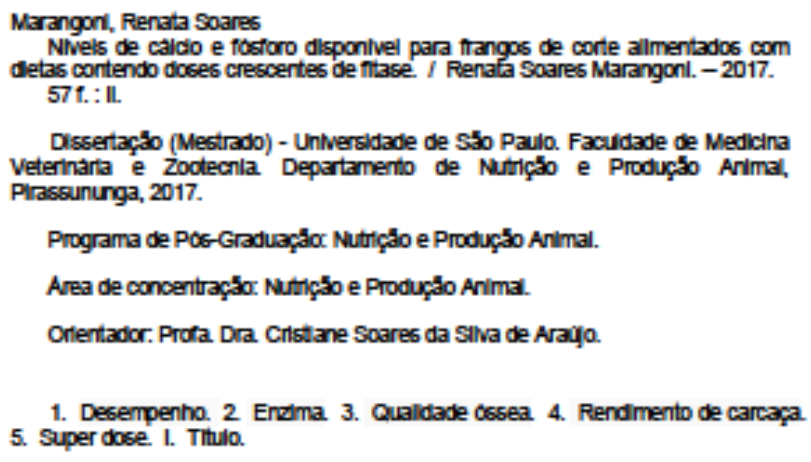 \\
\hline
\end{tabular}




\section{CERTIFICADO}

Certificamos que a proposta intitulada "Niveis de cálcio e fósforo disponível para frangos de corte alimentados com doses crescentes de fitase", protocolada sob o CEUA n 8982171115, sob a responsabilidade de Cristiane Soares da Silva Araújo e equipe; Renata Soares Marangoni; Carlos Alexandre Granghelli; Priscila Spinola Zorzetto - que envolve a produçāo, manutençāo e/ou utilização de animais pertencentes ao filo Chordata, subfilo Vertebrata (exceto o homem), para fins de pesquisa cientifica ou ensino - está de acordo com os preceitos da Lei 11.794 de 8 de outubro de 2008, com o Decreto 6.899 de 15 de julho de 2009, bem como com as normas editadas pelo Conselho Nacional de Controle da Experimentaçăo Animal (CONCEA), e foi aprovada pela Comissão de Ettica no Uso de Animais da Faculdade de Medicina Veterinária e Zootecnia da Universidade de São Paulo (CEUAFMVZ) na reuniảo de 15/08/2016.

We certify that the proposal "Levels of calcium and phosphorus available for broilers fed increasing doses of phytase", utilizing protocol number CEUA 8982171115, under the responsibility of Cristiane Soares da Silva Araújo and team; Renata Soares Marangoni; Carlos Alexandre Granghelli; Priscila Spinola Zorzetto - which involves the production, maintenance and/or use of animals belonging to the phylum Chordata, subphylum Vertebrata (except human beings), for scientific research purposes or teaching - is in accordance with Law 11.794 of October 8, 2008, Decree 6899 of July 15, 2009, as well as with the rules issued by the National Council for Control of Animal Experimentation (CONCEA), and was approved by the Ethic Committee on Animal Use of the School of Veterinary Medicine and Animal Science (University of São Paulo) (CEUAFMVZ) in the meeting of 08/15/2016.

Finalidade da Proposta: Pesquisa

Vigência da Proposta: de 01/2016 a 03/2016

Área: Fmvz

Resumo: Um experimento será realizado com o objetivo de avaliar a redução dos níveis de cálcio e fósforo disponivel em dietas suplementadas com doses crescentes de fitase para frangos de corte. Serä́o utilizados 1152 pintainhos machos Cobb distribuídos em um delineamento inteiramente casualizado em esquema fatorial $3 X 4$ (três niveis de cálcio e fósforo disponivel e quatro niveis de fitase) com 12 tratamentos e oito repetiçōes de 12 aves cada. Os tratamentos experimentais seräo: T1 Q Dieta com niveis de cálcio e fósforo disponivel de acordo com o proposto por Rostagno et al. (2011) para as diferentes fases; T2 D Dieta com redução de $10 \%$ dos niveis cálcio e fósforo disponivel proposto por Rostagno et al. (2011) para as diferentes fases; T3 D Dieta com reduçăo de $20 \%$ dos niveis cálcio e fósforo disponivel proposto por Rostagno et al. (2011) para as diferentes fases: T4 D Dieta do T1 + fitase 500 FTU/Kg de raçāo; T5 Dieta do T2 + fitase 500 FTU/Kg de raçāo; T6 [ Dieta do T3 + fitase 500 FTU/Kg de ração; T7 0 Dieta do $\mathrm{T} 1$ + fitase $1.000 \mathrm{FTU} / \mathrm{Kg}$ de raçăo: T8 D Dieta do T2 + fitase $1.000 \mathrm{FTU} / \mathrm{Kg}$ de raçăo; T9 D Dieta do T3 + fitase $1.000 \mathrm{FTU} / \mathrm{Kg}$ de raçẫo: $\mathrm{T} 10$ Dieta do $\mathrm{T} 1$ + fitase $1.500 \mathrm{FTU} / \mathrm{Kg}$ de ração: T11 Q Dieta do T2 + fitase $1.500 \mathrm{FTU} / \mathrm{Kg}$ de raçăo: T12 0 Dieta do T3 + fitase $1.500 \mathrm{FTU} / \mathrm{Kg}$ de ração. As aves serão pesadas aos 7, 21 e 42 dias. As dietas serão a base de milho e farelo de soja. As características de desempenho serão avaliadas. Aos 42 dias de idade será realizado o rendimento de carcaça e de cortes

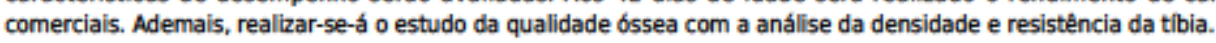

Local do experimento: Laboratório de Pesquisa em Aves

Săo Paulo, 01 de setembro de 2016

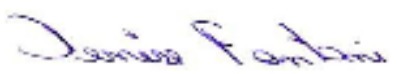

Profa. Dra. Denise Tabacchi Fantoni Presidente da Comissāo de Etica no Uso de Animais Faculdade de Medicina Veterinária e Zootecnia da Universidade de São Paulo

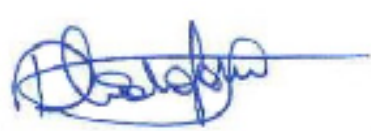

Roseli da Costa Gomes

Secretaria Executiva da Comissäo de Ética no Uso de Animais Faculdade de Medicina Veterinária e Zootecnia da Universidade de Săo Paulo

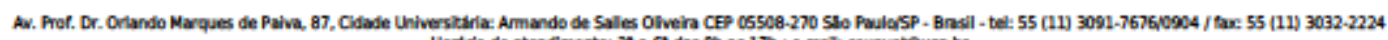
Hordrio de atendimento: 20 a 6 das 8 h as 17 : : - mall: ceuavebousp br 


\section{FOLHA DE AVALIAÇÃO}

Nome: MARANGONI, Renata Soares

Título: Níveis de cálcio e fósforo disponível para frangos de corte alimentados com dietas contendo doses crescentes de fitase

Dissertação apresentada ao Programa de Pós-Graduação em Nutrição e Produção Animal da Faculdade de Medicina Veterinária e Zootecnia da Universidade de São Paulo para obtenção do título de Mestre em Ciências.

Data:

Banca Examinadora

Prof.Dr.

Instituição:

Assinatura:

Prof.Dr.

Instituição:

Assinatura:

Prof.Dr.

Instituição:

Assinatura: 


\section{Dedicatória}

Primeiramente à Deus, fonte de minha inspiração e força.

Aos meus pais José Luiz e Vera Helena pelos ensinamentos, apoio e carinho sempre.

Ao meu marido Samuel pelo amor, companheirismo e cumplicidade.

E ao meu filho Davi a quem espero com grande amor. 


\section{Agradecimentos}

À Deus pela proteção em todos os momentos de minha vida;

Aos meus pais José Luiz e Vera, minhas irmãs Andréia e Érika, meus cunhados Jefferson e Fábio e aos meus sobrinhos Lívia e Lucas.

Ao meu marido Samuel pelo apoio de sempre e ao meu filho Davi por chegar em um momento tão importante da minha vida.

À família Marangoni.

Ao Departamento de Nutrição e Produção Animal - VNP da Faculdade de Medicina Veterinária e Zootecnia da Universidade de São Paulo, seus funcionários e corpo docente.

À De Heus Indústria e Comércio de Nutrição Animal Ltda. em nome do presidente Hermanus Wigman, por apoiar e permitir a realização desse aperfeiçoamento.

À professora Cristiane, pela orientação, apoio, paciência, amizade, confiança, ensinamentos e abertura de horizontes.

Ao professor Júlio e ao amigo Carlos pela ajuda na realização da análise estatística.

Aos funcionários do aviário: Edinho, China, Diego, Pedro, Joel e Paulo.

A todos os amigos da USP que me ajudaram muito nesse trabalho, Priscila, Carlos, Brunna, Fabrícia, Sara, Paulo e Rafael pela amizade, apoio na condução do experimento e pela ajuda na realização das análises.

Aos amigos da De Heus que muito me apoiaram tecnicamente e moralmente.

À todas as pessoas que contribuirão para o desenvolvimento deste trabalho e sempre estiveram ao meu lado me auxiliando e cooperando para a finalização deste trabalho.

A todos vocês meu muito obrigada! 


\section{Resumo}

MARANGONI, R. S. Níveis de cálcio e fósforo disponível para frangos de corte alimentados com dietas contendo doses crescentes de fitase, Dissertação (Mestrado em Ciência Animal) - Faculdade de Medicina Veterinária e Zootecnia. Universidade de São Paulo, Pirassununga, 2017.

Este experimento foi realizado com o objetivo de avaliar a redução dos níveis de cálcio e fósforo disponível em dietas suplementadas com doses crescentes de fitase para frangos de corte. Foram utilizados pintinhos machos da linhagem Cobb $(n=1152)$ distribuídos em um delineamento inteiramente casualizado em esquema fatorial $3 \times 4$ (três níveis de cálcio e fósforo disponível e quatro níveis de fitase) com 12 tratamentos e oito repetições de 12 aves cada. Os tratamentos experimentais foram: T1 - Dieta com níveis de cálcio e fósforo disponível de acordo com o proposto por Rostagno et al. (2011) para as diferentes fases; T2 - Dieta com 90\% dos níveis de cálcio e fósforo disponível proposto por Rostagno et al. (2011) para as diferentes fases; T3 - Dieta com 80\% dos níveis cálcio e fósforo disponível proposto por Rostagno et al. (2011) para as diferentes fases; T4 - Dieta do T1 + fitase 500 FTU/Kg de ração; T5 - Dieta do T2 + fitase 500 FTU/Kg de ração; T6 - Dieta do T3 + fitase 500 FTU/Kg de ração; T7 Dieta do T1 + fitase $1.000 \mathrm{FTU} / \mathrm{Kg}$ de ração; T8 - Dieta do T2 + fitase $1.000 \mathrm{FTU} / \mathrm{Kg}$ de ração; T9 - Dieta do T3 + fitase 1.000 FTU/Kg de ração; T10 - Dieta do T1 + fitase 1.500 FTU/Kg de ração; T11 - Dieta do T2 + fitase 1.500 FTU/Kg de ração; T12 - Dieta do T3 + fitase 1.500 FTU/Kg de ração. As dietas foram a base de milho e farelo de soja. As aves foram pesadas aos 7, 21 e 42 dias de idade. As características de desempenho foram avaliadas e, aos 42 dias de idade, foram avaliados o rendimento de carcaça e os cortes comerciais. $O$ estudo da qualidade óssea, como a análise da densidade e resistência da tíbia, também foi realizado. Com o aumento das inclusões de fitase houve aumento linear de ganho de peso médio aos 7 dias e aos 21 dias. Da mesma forma, houve redução linear na conversão alimentar aos 21 dias, com o aumento dos níveis de fitase. Considerando o período de 1 a 42 dias, a dieta sem inclusão da enzima apresentou resultados inferiores ao uso das dietas contendo fitase, resultando em um índice de eficiência produtiva com melhores resultados em dietas contendo 500 e 1500 FTU/Kg de ração da enzima. Houve interação entre o nível de cálcio e fosforo na dieta e adição de fitase para os parâmetros de ganho de peso e resistência óssea que neste trabalho foi representada pela força máxima $(\mathrm{N})$. 
Palavras chave: Desempenho. Enzima. Qualidade óssea. Rendimento de carcaça. Super dose. 


\section{ABSTRACT}

MARANGONI, R. S. Reduction of calcium and available phosphorus for broilers fed diets containing increased levels of phytase - Dissertation (Masters of Animal Science). Animal Science and Veterinary Medicine Department. University of São Paulo, Pirassununga, 2017

This trial was conducted with the objective of evaluating the reduction of calcium and phosphorus available for broilers fed diets containing increased levels of phytase. One thousand and one hundred and fifty-two male chicks Cobb-500 ( $n=1152$ ) were submitted to a completely randomized factorial $3 \times 4$ (three levels of calcium and phosphorus available and four levels of phytase and were distributed among 12 treatments and 8 replicates with 12 broilers each replicate. The experimental treatments were: T1 - diet containing calcium and phosphorus availableas proposed by Rostagno et al. (2011) for different phases; T2 - diet containing 90\% of calcium and phosphoru available in the diet as proposed by Rostagno et al. (2011) for different phases; T3 - diet containing $80 \%$ of calcium and available phosphorus in the diet as proposed by Rostagno et al. (2011) for different phases; T4 - T1 Diet + phytase 500 FTU/Kg diet; T5 - T2 Diet + phytase 500 FTU/Kg diet; T6 - T3 Diet + phytase 500 FTU/Kg diet; T7 - T1 Diet + phytase 1.000 FTU/Kg diet; T8 - T2 Diet + phytase 1.000 FTU/Kg diet; T9 - T3 Diet + phytase 1.000 FTU/Kg diet; T10 - T1 Diet + phytase 1.500 FTU/Kg diet; T11 - the T2 diet + phytase 1.500 FTU/Kg diet; T12 - T3 Diet + phytase 1.500 FTU/Kg diet. The diets were corn and soybean meal - based. The broilers were weighed at 7, 21 and 42 days of age. Performance traits s were evaluated and, at 42 days of age. Carcass yield and commercial cuts were also evaluated. Furthermore, a bone quality study, with the analysis of density and tibial resistance, were performed. The increased levels of phytase in the diets determined a linear increased in average weight gain at 7 and 21 days of age. Likewise, the increased levels of phytase in the diets reduced linearly the feed conversion at 21 days of age. Considering the period from day 1 to day 42 the diets without phytase determined inferior results than the diets with phytase inclusion. The better results were found when the diets have between 500 and 1500 FTU of phytase per kg of concentrate. There were an interaction between the calcium and phosphorus 
levels with phytase concentration for weight gain e bone resistance. In this work, those parameters were represented by the maximum strength $(\mathrm{N})$.

Keywords: Bone quality. Carcass yield. Enzyme. Performance. Superdose 


\section{LISTA DE TABELAS}

Tabela 1. Médias semanais de temperaturas e umidade relativas no galpão experimental no período de 1 a 42 dias de idade.

Tabela 2. Descrição dos tratamentos experimentais

Tabela 3. Composição percentual e níveis nutricionais calculados das dietas experimentais para frangos de corte na fase pré inicial (1-7 dias)

Tabela 4. Composição percentual e níveis nutricionais calculados das dietas experimentais para frangos de corte na fase inicial (8-21 dias)

Tabela 5. Composição percentual e níveis nutricionais calculados das dietas experimentais para frangos de corte na fase de crescimento (22-35 dias)

Tabela 6. Composição percentual e níveis nutricionais calculados das dietas experimentais para frangos de corte na fase de abate (36-42 dias)

Tabela 7. Níveis de Ca e Pd e uso de diferentes níveis de inclusão da enzima fitase em dietas para frangos de corte sobre o desempenho

Tabela 8. Níveis de Ca e Pd e uso de diferentes níveis de inclusão da enzima fitase em dietas para frangos de corte sobre o rendimento de carcaça.

Tabela 9. Níveis de Ca e Pd e uso de diferentes níveis de inclusão da enzima fitase em dietas para frangos de corte sobre a qualidade óssea 


\section{LISTA DE FIGURAS}

Figura 1. Reações sucessivas catalisadas pela fitase ………………………..........30

Figura 2. Densitômetro modelo DPX-Alpha, Lunar® ............................................. 41

Figura 3. Máquina universal de ensaio $\mathrm{EMIC} \otimes$, modelo DL 3000, em ensaio mecânico de flexão de três pontos da tíbia direita 


\section{LISTA DE GRÁFICOS}

Gráfico 1. Efeito dos níveis de Ca e Pd nas dietas e a adição de diferentes níveis de fitase sobre o ganho de peso (Kg/dia) .................................................................17

Gráfico 2. Efeito dos níveis de $\mathrm{Ca}$ e Pd nas dietas e a adição de diferentes níveis de fitase sobre a força máxima $(\mathrm{N})$ 


\section{SUMÁRIO}

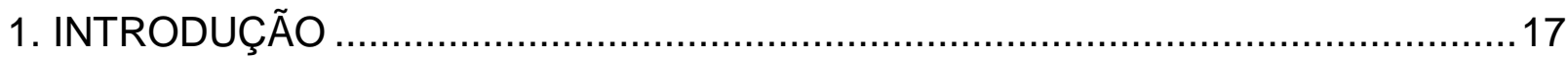

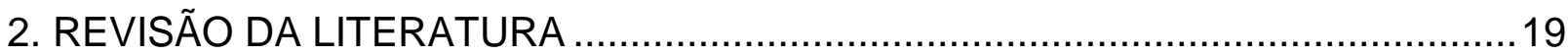

2.1 Uso de cálcio e fósforo nas dietas para frangos de corte ................................19

2.2 Considerações sobre o fitato ..............................................................22

2.3 Utilização da enzima fitase para frangos de corte..........................................25

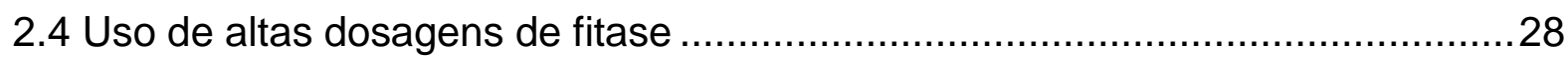

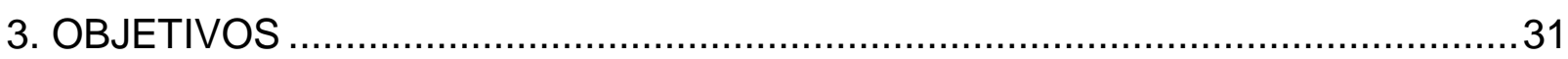

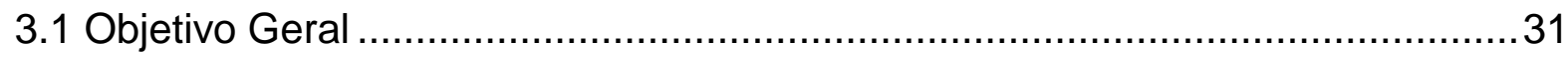

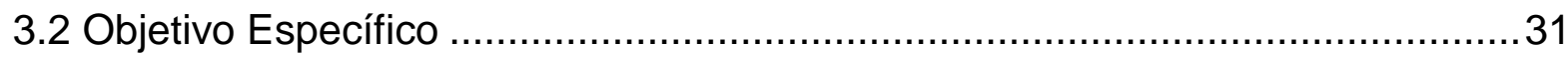

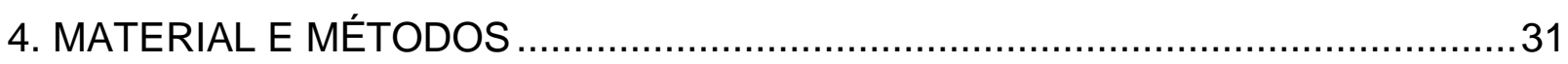

4.1 Animais, manejo, delineamento experimental e dietas …................................31

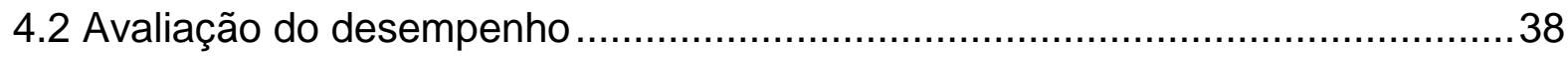

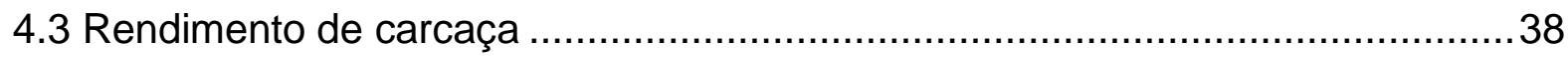

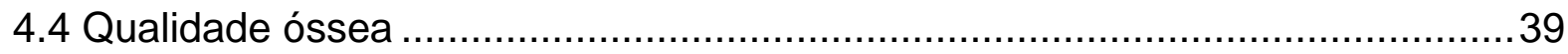

4.4.1 Conteúdo e densidade mineral óssea......................................................39

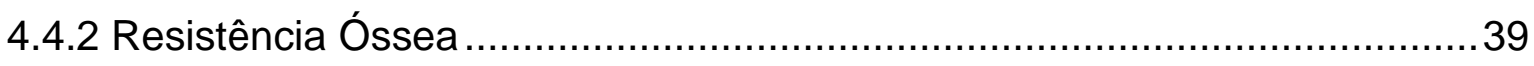

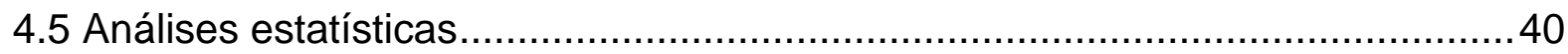

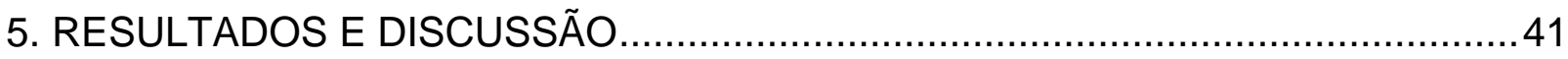

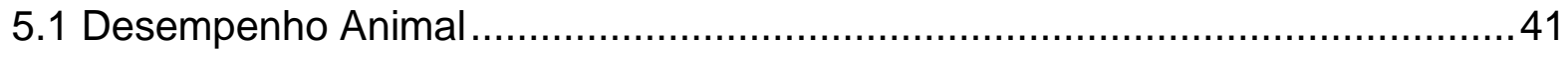

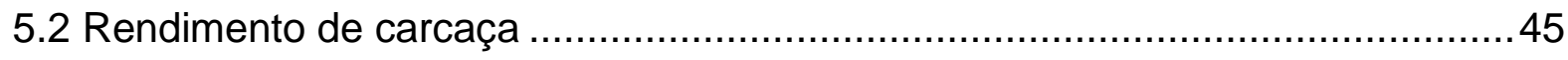

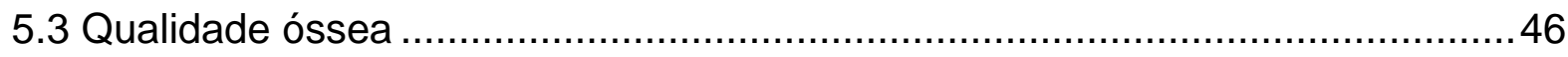

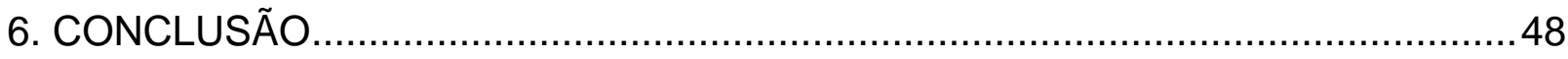

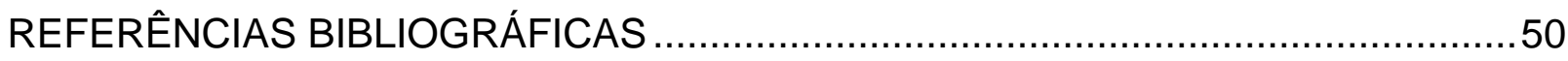




\section{INTRODUÇÃO}

Nas últimas três décadas, a avicultura brasileira tem apresentado altos índices de crescimento. Neste contexto, o frango de corte conquistou os mais exigentes mercados. Em 2016, a produção brasileira de frangos de corte superou 13,1 milhões de toneladas - assumindo o segundo lugar mundial, que antes era da China. Atualmente, mais de 150 mercados são importadores da carne de frango do Brasil. Pelos portos do país, são quase 4 milhões de toneladas embarcadas anualmente, quase um terço de tudo o que se produz no país. (ABPA, 2016)

Diante dessas informações, devido às constantes e rápidas evoluções genéticas que vem ocorrendo em frangos de corte, vale ressaltar que, várias pesquisas têm sido desenvolvidas para determinar as exigências nutricionais das aves em diferentes linhagens, com objetivo de se obter um programa nutricional de menor custo, mas que permita o máximo aproveitamento do potencial genético da ave.

No corpo dos animais, há cerca de 20 minerais que são essenciais para a manutenção e o funcionamento normal. A falta ou quantidades insuficientes destes resultam em sintomas de deficiência de minerais, reduzindo o desempenho. Quantidades em excesso, por outro lado, também levam a redução no desempenho pela ocorrência da toxidez. (McDowell, 2003; Underwood; Suttle, 1999; Richards et al., 2010).

Dentre os minerais essenciais, o cálcio $(\mathrm{Ca})$ tem um papel de destaque já que participa do desenvolvimento animal como constituinte de ossos, e consequentemente para uma ótima taxa de crescimento. Além disso, atua diretamente na regulação das funções nervosas, musculares e na ativação enzimática. Segundo Klasing (1998), o Ca é o mineral metabolicamente mais ativo, com um complexo sistema regulatório.

A suplementação de $\mathrm{Ca}$ depende da variabilidade e da disponibilidade de ingredientes nas rações, do potencial genético dos animais, do nível de energia da dieta, de doenças e desafio sanitário do ambiente, da densidade populacional, da ambiência, do crescimento compensatório, das interações nutricionais e/ou alimentares, do manejo e nível de estresse na criação, da suplementação de vitamina D, da integridade do intestino, fígado e rins, entre outros (McDowell, 1992). 
Uma das fontes minerais de Ca inorgânico mais utilizadas e de baixo custo, pois ocorre abundantemente na natureza, é o calcário calcítico. Normalmente, não há preocupação dos nutricionistas com o excesso de Ca na ração em virtude do seu baixo custo e por não apresentar toxicidade, embora alguns trabalhos, como a pesquisa Edwards Jr. \& Veltmann (1983) observaram que os níveis de Ca e Fósforo (P) na ração para frangos influenciaram a utilização de $P$ fítico. Ademais, Sebastian et al. (1997) observaram bons resultados da fitase em dietas com níveis baixos de $\mathrm{P}$ e $\mathrm{Ca}$.

Por outro lado, o excesso de Ca na dieta também interfere na disponibilidade de outros minerais como P, zinco ( $Z n)$ e manganês $(M n)$ (Schoulten et al., 2002). A quantidade excessiva de alguns minerais pode ser tóxica ou agir como antagonista de outros minerais, tal como o magnésio que, em excesso, atua como antagonista de vários minerais inclusive o Ca (Georgievskii, 1982).

O P é responsável por vários processos metabólicos e também essencial para a utilização e transferência de energia na forma de ATP. Na determinação da exigência nutricional de $\mathrm{P}$ para frangos de corte, deve-se recomendar um nível de $\mathrm{P}$ disponível (Pd) suficiente para um ótimo desempenho das aves e que garanta uma boa formação e resistência óssea. Por outro lado, é importante observar que, a suplementação de $P$ acima das necessidades resulta em excreção de níveis elevados, poluindo fluxos de água (Santos, 2008).

Do custo total da produção avícola, cerca de $70 \%$ é atribuído à alimentação, sendo que dentre os seus componentes, as fontes de energia e de proteína são os ingredientes mais onerosos, seguidos pela de P (Brugalli et al., 1999; Runho et al., 2001; Alvarenga et al., 2008). Além do custo elevado para atender as exigências de $P$ das aves, existe ainda a preocupação pela contribuição desse nutriente com a contaminação ambiental, pela excreção do $P$ não absorvido, o fitato, presente nos alimentos vegetais. Para contornar este problema, muitas pesquisas têm sido realizadas visando diminuir o $\mathrm{P}$ excretado pelas aves sem comprometer o desempenho animal Pinheiro, S. R. F., 2009). Nesse contexto, é importante ressaltar que a utilização de diferentes doses da enzima fitase vem sendo estudada de maneira bastante significativa na nutrição de aves, devido ao fato de auxiliar na disponibilização do $P$.

Além disso, alterar a formulação das dietas para reduzir o custo por tonelada de ração por meio da adição de enzimas digestivas tem sido uma das principais formas de utilização da fitase. Nesse caso, as dietas com níveis reduzidos de minerais, proteína e/ou aminoácidos e energia suplementadas com fitase possibilitam mesmo 
desempenho que uma dieta com níveis nutricionais recomendados (Zanella et al., 1999).

Ainda assim, conhecidas as importantes funções e atividades metabólicas do Ca e P é importante ressaltar que existem divergências entre os requerimentos nutricionais dos mesmos na alimentação de frangos de corte em diferentes países. Esse fato tem sido alvo de questionamentos entre os nutricionistas assim como o uso de doses de fitase acima da dosagem basal sugeridas pelos fornecedores.

Dessa forma, são necessários estudos para determinar a exigência de Ca e P para frangos de corte, relacionado ao uso enzima fitase, visando otimizar a produtividade e minimizar custos de produção.

\section{REVISÃO DA LITERATURA}

\subsection{Uso de cálcio e fósforo nas dietas para frangos de corte}

De acordo com Bertechini (2012) os minerais representam de 3 a $4 \%$ do peso vivo das aves e exercem funções essenciais na nutrição destes animais. Os macrominerais, com funções fisiológicas definidas, incluem $\mathrm{Ca}, \mathrm{P}$, potássio $(\mathrm{K})$, sódio $(\mathrm{Na})$, enxofre $(\mathrm{S})$, cloro $(\mathrm{Cl})$ e magnésio $(\mathrm{Mg})$, sendo que os dois primeiros apresentam maiores exigências dietéticas e também são os que mais afetam o desempenho das aves.

Além da formação e manutenção da estrutura óssea, o Ca é demandado pelas aves para adequado crescimento e utilização eficiente dos alimentos, formação da casca do ovo, transmissão de impulsos nervosos, coagulação sanguínea, contração muscular, ativação de sistemas enzimáticos e envolvimento com a secreção de diferentes hormônios (Underwood E Suttle, 1999; Sá et al., 2004,b).

A absorção de Ca ocorre ao longo de todo intestino delgado, principalmente, no duodeno e jejuno, tanto por difusão quanto pelo processo ativo. O mecanismo de absorção de Ca em nível celular intestinal ocorre via proteína transportadora de $\mathrm{Ca}$, a qual ativamente executa o carreamento de Ca do lúmen para o citosol, enquanto os canais iônicos de condução de Ca complementam o processo absortivo nas vilosidades intestinais (Macari et al., 2002). 
Uma vez dentro do citoplasma celular, uma proteína fixadora de Ca evita a formação de sais insolúveis intracelulares, e através da membrana basolateral, por proteínas de transporte ativo e Ca ATPase, finaliza-se o destino metabólico do Ca ou utilização pelo organismo (McDonald et.al., 1993).

Segundo Macari et al., (2002) a concentração do Ca sanguíneo é mantida em limites muito sensíveis pela ação de alguns hormônios que controlam a absorção, a excreção e o metabolismo ósseo. O hormônio paratireóideo (PTH) tem a ação de regular, indiretamente, a absorção de Ca através da hidroxilação da 25-(OH)-Vitamina $D$ à forma do composto ativo $\left(1,25-(\mathrm{OH})_{2} \mathrm{D}_{3}\right)$ nos rins. A calcitonina atua principalmente quando a concentração sérica de Ca está alta, diminuindo a absorção pelo trato gastrointestinal.

Nas rações para aves, o Ca é usualmente suplementado na forma de carbonato de cálcio proveniente do calcário calcítico, mas outras fontes podem ser utilizadas. De acordo com Reid \& Weber (1976), as fontes de Ca diferem em sua origem (deposição animal ou mineral) e no tamanho de sua partícula, resultando em características físicoquímicas diferentes.

Segundo Muniz, et al (2007), a deposição de Ca no esqueleto é mais intensa na fase de crescimento, assim, o conteúdo de Ca no organismo de aves jovens aumenta de maneira rápida de forma tal que uma suplementação inadequada durante esta fase terá como consequência um desequilíbrio na homeostase mineral e desenvolvimento inapropriado dos ossos.

Ca e P são elementos intimamente associados ao metabolismo, ocorrendo no organismo combinados entre si na maioria das vezes, de modo que a carência de um ou de outro na dieta limita o valor nutritivo de ambos (Maynard et al., 1984). Deficiências, excessos e imbalanços do $\mathrm{Ca}$ e $\mathrm{P}$ resultam em uma cascata de alterações, incluindo o aumento ou decréscimo da absorção desses minerais no lúmen intestinal (Weglarz; Angel, 2013). No entanto, o Ca em excesso pode agir como antagonista dificultando a absorção de alguns minerais tais como ferro (Fe), cobre (Cu), Zn, Mg, Na, K, entre outros (Smith \& Kabaja, 1984; Waldroup, 1996). Desta maneira, pode-se reforçar a importância pela busca por alternativas nutricionais que considerem a otimização da absorção de minerais pelo organismo das aves.

O Ca e o P dietéticos estão associados no metabolismo para a absorção, sendo preconizada uma relação de 2:1 (Ca:P) para a otimização na taxa de absorção dos mesmos. Se não há equilíbrio de um destes elementos haverá interferência no 
processo de homeostase de ambos componentes (Andriguetto et al.; 1990). Waldroup et al. (1963) observaram que o requerimento para Ca ou $P$ não pode ser estabelecido, se não for especificado o nível de ambos. Frangos recebendo baixo nível de $\mathrm{P}$ na ração foram mais afetados pela mudança na relação $\mathrm{Ca}: \mathrm{P}$, de tal modo que, quando a ração apresentava baixo nível de $\mathrm{P}(<0,6 \%)$, os níveis mais altos de $\mathrm{Ca}$ induziram à diminuição no ganho de peso das aves, devido à redução na motilidade intestinal (Nelson \& Miles, 1972).

O P é componente essencial para a formação dos ossos e mantença, necessário para a formação do tecido muscular, componentes dos ácidos nucléicos no qual é fundamental no controle do metabolismo celular. Além disto, auxilia na manutenção osmótica e no balanço ácido-básico, é necessário para a formação dos fosfolipídeos, está envolvido no metabolismo de aminoácidos, e na transferência de energia como componente da molécula de trifosfato de adenosina (ATP) (Underwood, 1981).

Os ossos, além de serem componentes estruturais ou de suporte do corpo, servem como reserva de $\mathrm{Ca}$ e $\mathrm{P}$ e podem ser mobilizados ocasionalmente, quando o fornecimento desses minerais for inadequado para atender as necessidades do organismo (Maynard e Loosli, 1984). De acordo com Lopes (2009) o tecido ósseo sofre influência dos fatores endógenos e exógenos, como produção hormonal, nutrição e temperatura, durante todas as fases da vida, tendo a possibilidade de haver variações na massa óssea.

Umas das técnicas mais utilizadas para mensuração da qualidade óssea é a densitometria óssea. A densitometria óssea é uma técnica que devido a sua alta precisão em detectar variações de ganho ou perda de massa óssea, é útil para o acompanhamento das doenças que afetam a mineralização óssea e o tratamento destas (Barreiro et al, 2009). A técnica baseia-se na comparação da imagem radiográfica do osso com a imagem radiográfica de uma escada de alumínio prédefinida, já que a densidade deste metal é muito semelhante à densidade da hidroxiapatita existente no osso (Amoroso, 2009).

A absorção do $P$ na dieta é de 60 a $70 \%$ e se realiza por um sistema de cotransporte ativo, utilizando $\mathrm{Na}$ ou simplesmente por um processo passivo de difusão. $\mathrm{O}$ processo de absorção ocorre maioritariamente na porção proximal do duodeno (Rosol; Capen, 1997). Essa absorção é similar àquela para o $\mathrm{Ca}$, sendo estimulada pela vitamina $\mathrm{D}$. Em condições fisiológicas a absorção líquida de fosfato é mais linear com 
o conteúdo dietético do P. A absorção torna-se difícil quando se formam quelatos com cátions, como Ca ou alumínio (Al) (Gómez Alonso, et al, 2004).

Em rações formuladas para as aves, o fornecimento de $\mathrm{Pd}$ pelas fontes de origem vegetal não são suficientes para atender as exigências nutricionais para o adequado desempenho e mineralização óssea, havendo necessidade de suplementação com fontes de $\mathrm{P}$ na forma inorgânica, que geralmente apresentam diferentes valores de biodisponibilidade. (Rostagno et al., 2000). Por esta razão, Lima (1995) confirma a importância do uso da enzima fitase, uma vez que, o aumento na disponibilidade de $P$ fítico resulta em redução da necessidade de suplementação do $P$, que é o terceiro maior custo (depois da energia e proteína) nas dietas de frangos de corte.

De acordo com Bertechini (2013), sempre irá existir um nível ideal de Ca para que se tenha máxima absorção do $\mathrm{P}$ e esse nível nem sempre é $\mathrm{o}$ ideal para o desempenho das aves. Por isso, é que são encontrados valores discrepantes de taxa de absorção ou biodisponibilidade de fontes de $\mathrm{P}$, decorrentes de fatores relacionados ao $\mathrm{Ca}$, principalmente no que se refere ao nível de solubilidade.

Schoultem et al. (2002) verificaram que tanto os níveis mais altos como os níveis mais baixos de $\mathrm{Ca}$ influenciaram negativamente a absorção de $\mathrm{P}$. Segundo os autores, a redução da absorção de $\mathrm{P}$, quando o nível de $\mathrm{Ca}$ é muito baixo, se deve ao desequilíbrio da relação $\mathrm{Ca}$ e $\mathrm{P}$ total da ração. Por outro lado, níveis elevados de $\mathrm{Ca}$ inibem o efeito da fitase sobre o aproveitamento do fitato.

Segundo Macari et al., (2002) um fator de grande relevância no processo de absorção do $\mathrm{P}$ é a sua disponibilidade no lúmen intestinal. A presença do $\mathrm{P}$ na forma fítica, resistente à hidrólise nos monogástricos, além de não permitir o uso do $\mathrm{P}$ pelos animais, compromete a absorção de $\mathrm{Ca}$ e de outros minerais como $\mathrm{Zn}$ e o $\mathrm{Cu}$, podendo diminuir a digestibilidade de alguns aminoácidos. Esses efeitos podem ser amenizados através da utilização de enzimas exógenas, como a fitase, que é capaz de catalisar o P fítico liberando o P. (Edwards, 1993).

\subsection{Considerações sobre o fitato}

O P presente nos grãos e cereais da ração encontra-se na forma de ácido fítico, com aproximadamente $28,2 \%$ de $P$. Porém, as aves não conseguem aproveitar esse 
$P$, pois elas não têm a enzima fitase, que é necessária para metabolizar e liberar o $P$ do ácido fítico, para que esse mineral seja assimilado pelo organismo (Silva et al., 2008).

O fitato é sintetizado a partir da molécula de mio-inositol em uma série de etapas de fosforilações, e é composto por 6 fosfatos. Entretanto, o P presente na molécula de fitato é pouco disponível para os animais e pode reduzir a digestibilidade de outros nutrientes (Dersjant-Li et al., 2015).

O ácido fítico possui alto potencial para complexar nutrientes (íons e moléculas). O número de cargas iônicas no fosfato de mio-inositol influencia sua capacidade complexante e a desprotonação dos grupos fosfatos está intimamente ligada ao pH na qual a molécula se encontra (Naves, 2012). O fitato forma complexos com cátions multivalentes, formando quelatos insolúveis quando em pH neutro (Selle \& Ravidran, 2007).

Portanto, o fitato ou $P$ fítico é a designação dada ao $P$, que faz parte da molécula do ácido fítico (hexafosfato de inositol) encontrado nos vegetais. Por causa do seu grupo ortofosfato, altamente ionizado, esse complexa-se com uma variedade de cátions ( $\mathrm{Ca}, \mathrm{Fe}, \mathrm{Cu}, \mathrm{Zn}$, entre outros), o grupo amina de alguns aminoácidos (lisina, arginina, histidina) e, ainda, moléculas conjugadas de glicose, especialmente no amido. Esse complexo categoriza o fitato como um fator antinutricional, por diminuir a disponibilidade de minerais, além de proteína e energia (Morris, 1986). A molécula de fitato apresenta alto teor de $\mathrm{P}(28,2 \%)$, com alto potencial de quelação, como mencionado anteriormente, (Keshavarz, 1999), consitui a maior parte do P total, por volta de dois terços em ingredientes de origem vegetal (Simons \& Verteegh, 1990).

Conforme Benevides et al. (2011), no processo de fermentação e digestão de sementes, uma pequena porção do ácido fítico (IP6, ou hexafosfato de mio inositol) é fosforilada, resultando em estruturas que tem propriedades anti-nutricionais, tais como o monofosfato (IP1), inositol difosfato (IP2), trifosfato (IP3), tetrafosfato (IP4) e pentafosfato (IP5). A quantidade e os compostos nutricionais que sofrem ação negativa para a biodisponibilidade intestinal são dependentes do nível de fosforilação alcançado na molécula de ácido fítico.

O pentafosfato (IP5) possui ação negativa para a biodisponibilidade de nutrientes durante o processo de digestão, pois forma complexos de ligações com minerais, como o $\mathrm{Ca}, \mathrm{Zn}, \mathrm{Mg}, \mathrm{Fe}, \mathrm{Cu}$, dando origem a precipitados minerais que não são absorvidos pelo organismo (Benevides et al., 2011). 
O ácido fítico das sementes pode interagir com outros componentes dos alimentos no trato digestório dos animais monogástricos. Estas interações são complexas e dependem de alguns fatores tais como $\mathrm{pH}$ do aparelho digestório, a presença de outros alimentos que competem com o ácido fítico e as ligações minerais. (Konietzny et al., 2002). Santos (2012) mostraram que a afinidade do fitato a cátions no trato gastrointestinal varia de acordo com o $\mathrm{pH}$, podendo estar relacionado com a constante de dissociação da molécula (pKa), o que significa que o fitato pode estar levemente carregado negativamente (em $\mathrm{pH}$ ácido) ou fortemente carregado negativamente (em pH neutro/alcalino). Desta maneira, a afinidade do fitato aos cátions da dieta muda de acordo com o $\mathrm{pH}$.

O fitato proveniente da dieta pode se ligar à pepsina presente no proventrículo das aves, formando um complexo pepsina-fitato no trato digestivo, que resulta em hipersecreção de ácido clorídrico e pepsina, porém, reduzindo a atividade de pepsina no proventrículo devido à ligação com o fitato (Liu et al., 2008a). Desta forma, quando a digesta chega ao intestino delgado, o pH está reduzido devido à hipersecreção do ácido clorídrico. Este quadro prejudica a digestão e absorção de proteínas e aminoácidos, já que o baixo $\mathrm{pH}$ reduz a atividade das enzimas pancreáticas e da borda em escova. Como resposta fisiológica do organismo, o trato gastrintestinal passa a secretar maiores quantidades de mucina e bicarbonato de sódio no lúmen intestinal, elevando a secreção de aminoácidos endógenos e de sódio, respectivamente. Assim, ocorrem maiores perdas endógenas de aminoácidos que poderiam ser aproveitados pela ave, além de redução da atividade de transporte de nutrientes que dependem da bomba Na-K-ATPase, como peptídeos e glicose (Liu et al., 2008a).

Alguns níveis da dieta podem influenciar a utilização do $P$ fítico. Como já citado, a elevação da proporção de $\mathrm{Ca}$ e $\mathrm{P}$ reduz significativamente o desempenho de frangos em relação à base de milho e farelo de soja, suplementadas com fitase, provavelmente, em decorrência da reação do $\mathrm{Ca}$ com o ácido fitico, formando o fitato de $\mathrm{Ca}$, que precipita e não pode ser hidrolisado pela fitase. (Leeson, 1999),

Para determinar o fitato na matéria prima existem diversas metodologias disponíveis, tais como a precipitação pelo cloreto férrico, HPLC (high-performance liquid chromatography) e metodologias enzimáticas, as quais, devido aos altos custos, podem se tornar inviáveis. Além desses métodos, é possível realizar avaliação por NIRS (Nearlnfrared Reflectance Spectroscopy) (De Boever et al., 1994; Smith et al., 2001). 
Com a redução do aproveitamento de $\mathrm{P}$ pelos animais, ocorre maior excreção deste mineral, contribuindo para aumento nos níveis de poluição ambiental. Além disso, o desperdício de $\mathrm{P}$ ocasionado pela formação do complexo $\mathrm{P}$ fitato pode comprometer a rentabilidade econômica da produção, devido à elevação do custo de produção pelo uso de ingredientes contendo fontes de $\mathrm{P}$ inorgânico, já que este mineral é considerado o terceiro mais oneroso em dietas para aves (Woyengo \& Nyachoti, 2011). Desta maneira, a utilização da enzima fitase na dieta de frangos de corte é uma ferramenta que ajuda na otimização da utilização deste mineral, reduzindo a excreção do mesmo no ambiente além de possibilitar a diminuição dos custos de produção.

\subsection{Utilização da enzima fitase para frangos de corte}

Nos últimos anos, a avicultura evoluiu muito se adequando às técnicas que possibilitam melhoria da eficiência produtiva. A alimentação é o fator de maior influência no custo de produção representando cerca de 60 a $75 \%$, com isso, pequenas melhorias na eficiência de utilização dos nutrientes podem resultar em grandes economias.

Uma ferramenta nutricional que vem demonstrando resultados satisfatórios é a inclusão de enzimas exógenas na alimentação de frangos de corte, com intuito de melhorar a eficiência alimentar das aves pelo aumento da digestão dos alimentos e redução na perda de nutrientes e, consequentemente, elevado potencial de redução da poluição ambiental causada pelo excesso de nutrientes contidos nas excretas das aves (Caires et al., 2008).

As enzimas exógenas são produzidas a partir da fermentação de microrganismos favoráveis como bactérias e fungos, principalmente dos gêneros Bacillus e Aspergillus, respectivamente. Os microrganismos são alterados para produzir entre 50 e 100 gramas de proteína ativa por litro de líquido fermentativo. As proteínas são então purificadas e resíduos indesejáveis são removidos do conteúdo produzido (Adeola \& Cowieson, 2011).

Estão disponíveis no mercado diferentes produtos com ações enzimáticas específicas como as fitases, amilases, xilanases, celulases, glucanases, dentre outras. Em geral, na alimentação animal os tipos de enzimas mais utilizadas são aquelas que quebram a fibra, as proteínas, o amido e o fitato, sendo que a fitase é a mais difundida na produção de frangos de corte. 
Fitases são enzimas que catalisam as reações da quebra das moléculas de fosfato ligadas ao ácido fítico. Algumas fitases iniciam o rompimento no grupo fosfato ligado ao Carbono-6 (C6) do anel do inositol enquanto outras começam o processo pelo Carbono-3 (C3). As fitases que iniciam a hidrólise pelo C6 são conhecidas como 6fitases e as que começam pelo $\mathrm{C} 3$ chamadas de 3 -fitases. Portanto, as fitases podem ser divididas em duas categorias de enzimas, de acordo com o local onde é iniciada a hidrólise da molécula de fitato: 3-fitase e 6-fitase, ou seja, iniciam a hidrólise do anel de mio-inositol hexafostafo nas posições 3 e 6 , respectivamente (Pallauf \& Rimbach, 1995). Atualmente estão disponíveis comercialmente, duas fitases derivadas a partir de fontes de fungos (Aspergillus niger e Peniophora Lycii), que são 3-fitases, ou de bactérias (Escherichia coli), que são 6-fitases.

As fitases (hexafosfato de mio-inositol fosfohidrolases) são enzimas amplamente encontradas nos microorganismos, plantas e certos tecidos animais, entretanto as fontes microbianas são as mais adequadas para a produção em escala comercial (Vats; Banerjee, 2004). Sua atividade é específica para determinadas reações e substratos, sendo que as enzimas digestivas possuem um sítio ativo que permite que elas atuem sobre determinada ligação química sob condições favoráveis de temperatura, umidade e pH (Penz Júnior, 1998).

Portanto, conhecer o substrato de atuação das enzimas é fundamental para que a atuação seja máxima, sendo, portanto, importante que se tenha conhecimento a respeito da composição dos ingredientes utilizados na ração, de modo que haja substrato disponível para a atuação da enzima exógena específica adicionada à dieta para maximizar seu aproveitamento e evidenciar seu benefício (Bao et al., 2013). A atividade desta enzima é expressa em FTU ou simplesmente $U$ (unidades de fitase ativa) e é definida como sendo a quantidade de enzima necessária para liberar um micromol de $\mathrm{P}$ inorgânico em um minuto num substrato de sódio-fitato, a temperatura de $37^{\circ} \mathrm{C}$ e pH 5,5 (Conte, 2000).

A tecnologia para a produção em escala comercial dessas enzimas evoluiu muito, tanto no que se refere às técnicas de obtenção, quanto à engenharia genética. Isso permite que se tenha enzimas produzidas por vários microrganismos geneticamente modificados ou não. No caso daqueles geneticamente modificados estes são resultantes em muitos casos da expressão do gene do Aspergilus fícus em outros fungos ou bactérias. Inicialmente, os processos de produção utilizavam o método de fermentação submersa, mas atualmente a fermentação no estado sólido tem 
despertado maior interesse, em função dos bons rendimentos apresentados (Silva et al, 2010).

Para reverter a deficiência de $\mathrm{P}$ na dieta, e atingir as necessidades nutricionais das aves, as rações são formuladas com adição de vitaminas e suplementação mineral, com fontes orgânicas de P (farinha de carne e ossos), e inorgânica (fosfato bicálcico). Os fosfatos são responsáveis pela despesa de quase $50 \%$ dos gastos com a suplementação das dietas (Pizzolante; Teixeira; Santos, 2002).

Além disso, visando redução do impacto ambiental, várias pesquisas têm sido realizadas com a adição de enzima exógena (fitase) em ração de aves, a qual atua na catalase do ácido fítico, liberando o $\mathrm{P}$ e outros nutrientes, tornando-os disponíveis ao metabolismo celular e, com isso, reduzindo o impacto ambiental provocado pela excreção deste nutriente (Lima, 1995).

Segundo Ahmad et al. (2000), houve efeito efetivo da fitase microbiana obtida do fungo Aspergillus niger na biodisponibilidade do $\mathrm{P}$ e Ca em frangos de corte entre até os 28 dias de idade. Estes autores observaram que a concentração de cinzas na tíbia e dedos dos frangos de corte que receberam dieta controle $(4,7 \mathrm{~g} / \mathrm{Kg}$ de $\mathrm{P}$ não-fítico) foi semelhante àquelas que receberam dieta com $20 \%$ a menos de $P$ não-fítico, porém suplementadas com fitase, indicando que a suplementação de fitase aumentou a utilização de $\mathrm{P}$ fítico.

Camden et al. (2001) observaram que a adição de fitase em rações com níveis reduzidos de $\mathrm{Pd}$ e $\mathrm{Ca}(0,36 \%$ e $0,81 \%$ respectivamente) para frangos de corte na fase inicial melhorou a retenção de nitrogênio e $P$, reduzindo esses elementos acumulados no esterco. Semelhantemente, Viveros et al. (2002) verificaram que a suplementação com fitase em rações com níveis reduzidos de $\mathrm{Pd}(0,35$ e 0,27\%) para frangos de corte, nesta mesma fase, aumentou a retenção de $\mathrm{Ca}, \mathrm{P}, \mathrm{Mg}$ e Zn.

Quanto à influência da fitase sobre a resistência óssea existem resultados controversos. Enquanto Denbow et al.(1998) observaram aumento na matéria mineral e resistência óssea das aves alimentadas com dietas contendo $0,20 \%$ de $\mathrm{Pd}$ e suplementada com 400, 800 ou $1200 \mathrm{U}$ de fitase ativa/kg da dieta, Johnston \& Soutern (2000) verificaram que mesmo suplementando as dietas deficientes em P com $600 \mathrm{U}$ de fitase a resistência óssea diminuiu.

A ausência de benefícios ao uso de enzimas exógenas, ou complexos enzimáticos, ou mesmo a inconsistência dos resultados, pode ser causada por fatores 
como valorização nutricional incorreta da enzima utilizada e principalmente pela qualidade e composição dos ingredientes utilizados na dieta (Bao et al., 2013).

Brenes et al. (2003) avaliaram o efeito da fitase microbiana na utilização de minerais em frango de corte em dietas com dois níveis de $\mathrm{Pd}(0,35 \%$ e $0,25 \%)$ e seis de fitase (0, 200, 400 e $600 \mathrm{FTU} / \mathrm{kg}$ de dieta). Estes autores concluíram que a adição de fitase com $200 \mathrm{FTU} / \mathrm{kg}$ em dieta à base de milho e farelo de soja com baixo nível de $\mathrm{Pd}$, melhorou o desempenho e incremento na utilização de $\mathrm{Ca}, \mathrm{P}$ e Zn.

Um dos fatores mais importantes é a relação de Ca e $\mathrm{P}$ na dieta, que deve estar em torno de 2:1, pois a elevação do nível de Ca na ração influencia negativamente a atividade da fitase, pois o excesso de Ca forma um precipitado de fitato de Ca que não pode ser quebrado pela ação da enzima fitase. Esse fator prejudica as diferentes fases de criação de frangos, pois não ocorre o fornecimento adequado desses minerais para atender as necessidades fisiológicas e produtivas das aves (Oliveira, 2011).

De acordo com Bedford (2000), não há quebra de $100 \%$ do fitato presente nos vegetais, bem como não ocorre a hidrólise completa das moléculas de fitato. A exigência nutricional de $\mathrm{P}$ muda conforme a idade da ave. Aves na fase inicial e de crescimento estão em processo de desenvolvimento da estrutura óssea e massa muscular, necessitando quantidades maiores de nutrientes e energia. $\mathrm{Na}$ fase final de criação, as aves podem aumentar o aproveitamento do $\mathrm{P}$ complexado ao ácido fítico, em conseqüência da plena atividade enzimática do sistema digestivo (Laurentiz et al., 2007).

Portanto, diversos fatores interferem na atividade das fitases e entre os fatores mais importantes estão a quantidade de fibra da ração, concentração e a fonte do substrato, relação $\mathrm{Ca}: \mathrm{P}$, temperatura na qual a ração foi fabricada, temperatura corporal dos animais, idade dos animais, conteúdo de vitamina $\mathrm{D}$ nas dietas e $\mathrm{pH}$.

\subsection{Uso de altas dosagens de fitase}

Como citado anteriormente, as fitases podem ser utilizadas como estratégia nutricional para reduzir a inclusão de determinados ingredientes, diminuir o custo de formulação da ração, a excreção de nutrientes ao ambiente e melhorar a disponibilidade de $\mathrm{P}$ fitico, forma complexada nos ingredientes vegetais e que não é utilizada pelas aves. 
A intensidade de ação desta enzima, entretanto, depende também de outros fatores, dentre os quais a relação entre $\mathrm{Ca}$ e $\mathrm{P}$ da ração, quanto maior a relação menor a quantidade de Pliberada (Beaulieu, 2005; Adeola, et al., 2006).

Um aspecto importante a considerar é o nível ideal de enzima a ser adicionado, de acordo com a redução nutricional estabelecida. Isso porque, a atuação da fitase é dose dependente e aumenta à medida que doses mais altas são adicionadas à dieta. Em contrapartida, à medida que os níveis nutricionais são reduzidos abaixo da exigência do animal, ocorre naturalmente, uma maior retenção do nutriente no organismo para que sejam mantidas as funções fisiológicas e neste caso, níveis mais altos de fitase podem ser necessários para que seja expresso o efeito da enzima. (Shoener et al., 1993).

Uma nova estratégia nutricional, chamada superdosagem, que pode potencializar o aumento da economia do custo da dieta bem como o desempenho da ave seria a inclusão de níveis mais elevados de fitase. De acordo com Walker, et al. 2014 os altos níveis de fitase podem hidrolisar quase que completamente o IP6, aumentar as concentrações de inositol na moela e promover melhoria do ganho de peso e da conversão alimentar de frangos sem efeitos adversos na porcentagem de cinzas na tíbia. Os benefícios com os maiores níveis de fitase podem estar associados com a destruição do fitato bem como o fornecimento de inositol em vez do excesso de $\mathrm{P}$ e Ca.

As reações sucessivas catalisadas pelas fitases são feitas por etapas e promovem a desfosforilação dos ésteres de mio-inositol fostato (IP6) até a liberação de cinco grupos fosfatos, restando apenas uma molécula de mio-inositol fosfato ligada a um grupo fosfato (mio-inositol monofosfato), no C2, por ser resistente à hidrólise enzimática (IP1) (Figura 1). Entretanto, as fitases exógenas utilizadas na nutrição animal não atingem este estágio de degradação por dependerem de características como temperatura adequada, $\mathrm{pH}$, conteúdo de minerais, entre outros (Selle \& Ravindran, 2007). 
Figura 1: Reações sucessivas catalisadas pela fitase

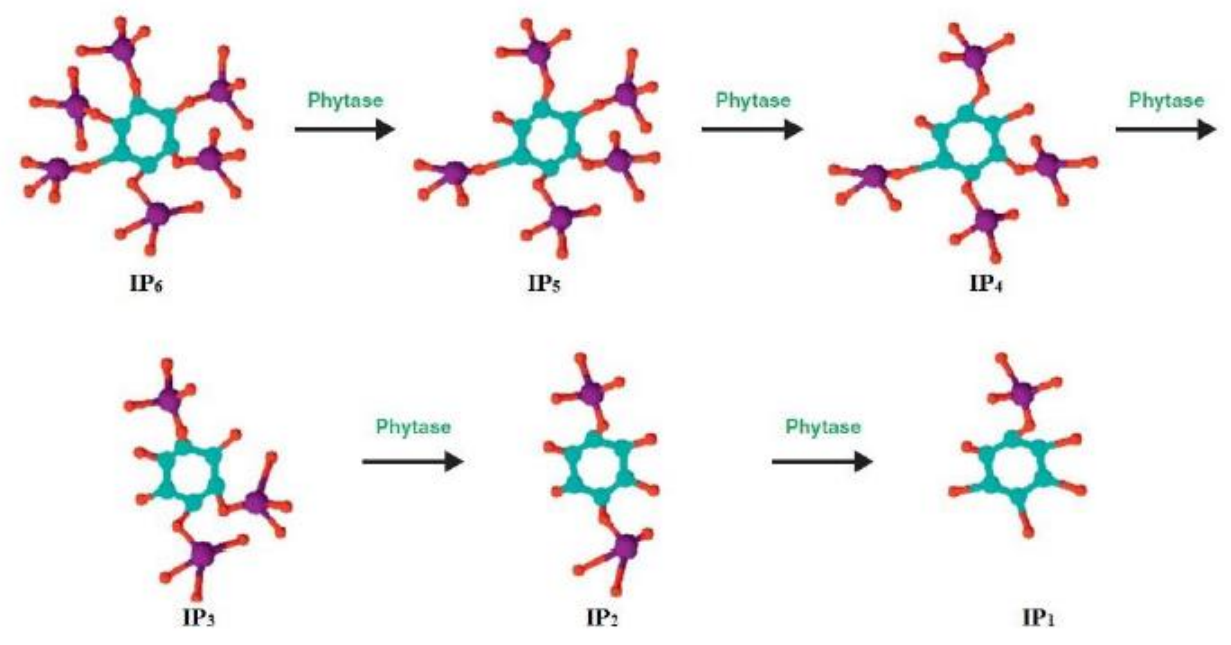

Fonte:(adaptado de KEBREAB et al., 2012)

Shirley \& Edwards Jr. (2003) verificaram que a suplementação de $1200 \mathrm{U} / \mathrm{kg}$ da dieta (acima do recomendado pelo fabricante) melhorou a retenção do $\mathrm{P}$ em $157 \%$, a retenção de $\mathrm{N}$ em 134\% e a energia metabolizável aparente (EMA) em 106\%. Entretanto, não é regra admitir que quanto mais altos os níveis da enzima, maior a disponibilidade de nutrientes, pois a inter-relação entre os cátions multivalentes fornecidos em uma dieta podem reprimir a atuação da fitase (Pointllart et al., 1984).

Alguns trabalhos demonstraram que com altos níveis de fitase, é possível diminuir a inclusão de ingredientes que oneram o custo de formulação, sem comprometer o desempenho e a digestibilidade de nutrientes. Denbow et al. (1995) trabalharam com 200, 400,600, 800, 1.000, $1.200 \mathrm{FTU} / \mathrm{Kg}$ em dietas para frangos contendo 0,$20 ; 0,27$ ou $0,34 \%$ de Pd. Foi observado aumento no ganho de peso e no consumo de ração em todos os níveis de $\mathrm{Pd}$, mas a máxima resposta foi obtida com a dieta que continha 0,20 de $P$ não fítico.

Managi \& Coon (2008) avaliaram dietas contendo $0,7 \%$ de $\mathrm{Ca}$ e $0,12 \%$ de $\mathrm{Pd}$ com 0,$250 ; 500 ; 700 ; 1.000 ; 1.500 ; 2.000$ e $5.000 \mathrm{FTU} / \mathrm{Kg}$ de fitase e observaram hidrólise do P fítico em 43,12; 68,12; 74,70; 85,02; 85,25; 92,77; 96,91 e 99,45\%, respectivamente. Portanto, a máxima retenção aparente do $\mathrm{P}$ foi obtida com a inclusão de fitase em $1.000 \mathrm{FTU} / \mathrm{Kg}$ de ração. 


\section{OBJETIVOS}

\subsection{Objetivo Geral}

O objetivo do presente trabalho foi avaliar a redução dos níveis de $\mathrm{Ca}$ e $\mathrm{Pd}$ em dietas de frangos de corte suplementadas com doses crescentes de fitase.

\subsection{Objetivo Específico}

Verificar o efeito da redução de níveis de $\mathrm{Ca}$ e $\mathrm{Pd}$ em dietas contendo doses crescentes de fitase para frangos de corte, sobre os aspectos:

- peso corporal peso das aves, ganho de peso, consumo de ração, conversão alimentar e fator de eficiência produtiva.

- qualidade óssea avaliada pela densidade mineral e resistência óssea.

\section{MATERIAL E MÉTODOS}

\subsection{Animais, manejo, delineamento experimental e dietas}

O experimento foi conduzido no Laboratório de Pesquisa em Aves do Departamento de Nutrição e Produção Animal da Faculdade de Medicina Veterinária e Zootecnia da Universidade de São Paulo, Campus Fernando Costa em Pirassununga no período de 20 de janeiro à 04 de março de 2016. Todos os procedimentos realizados foram aprovados pela Comissão de Ética no Uso de Animais - CEUA - FMVZ/USP, processo № 8982171115.

Foram alojados 1.152 pintos machos com um dia de idade da linhagem Cobb $\AA_{500}$, provenientes de um incubatório comercial, vacinados contra Marek e New Castle. No primeiro dia do experimento, eles foram selecionados de acordo com o peso corporal e, posteriormente a uniformização, foram distribuídos aleatoriamente.

As aves foram alojadas em galpão experimental, convencional com sistema de pressão positiva e nebulizador, com piso cimentado coberto por casca de arroz nova. Foram utilizados 96 boxes de 0,90 m x 1,40 m com 12 aves cada, sendo que cada boxe foi equipado com comedouro tubular e bebedouros tipo nipple. $\mathrm{O}$ controle do 
aquecimento, foi realizado através de lâmpadas de infravermelho e o programa de luz bem como as práticas de manejo adotados foram preconizados pelo manual da linhagem (COBB, 2012). Foram registradas diariamente a temperatura ambiente e a umidade relativa do ar com termômetro digital, colocados na altura das aves. (Tabela 1)

Tabela 1 - Médias semanais de temperaturas e umidade relativas no galpão experimental no período de 1 a 42 dias de idade.

\begin{tabular}{lllll}
\hline & \multicolumn{3}{c}{ Temperatura, ${ }^{\circ} \mathrm{C}$} & \multicolumn{2}{c}{ Umidade, $\%$} \\
\cline { 2 - 5 } Semanas & Máxima & Mínima & Máxima & Mínima \\
\hline $1^{\mathbf{a}^{\mathrm{a}}}$ & 30,6 & 24,3 & 69,4 & 58,1 \\
$2^{\mathrm{a}}$ & 30,0 & 24,0 & 73,4 & 59,1 \\
$3^{\mathrm{a}}$ & 31,3 & 22,8 & 80,3 & 61,5 \\
$4^{\mathrm{a}}$ & 30,4 & 22,7 & 83,3 & 64,9 \\
$5^{\underline{a}}$ & 29,1 & 23,2 & 84,1 & 73,4 \\
$6^{\underline{a}}$ & 29,8 & 23,8 & 82,8 & 67,7 \\
\hline
\end{tabular}

O delineamento experimental foi inteiramente casualizado em esquema fatorial 3x4 (três níveis de inclusão de $\mathrm{Ca}$ e $\mathrm{Pd}$ e quatro níveis de fitase) totalizando doze tratamentos e oito repetições. Os tratamentos experimentais estão descritos na Tabela 2.

O programa de arraçoamento foi dividido em quatro fases: pré inicial (Tabela 3), inicial (Tabela 4), crescimento (Tabela 5) e final (Tabela 6). As rações foram formuladas à base de milho e farelo de soja, sendo isocalóricas e isoproteicas. A composição percentual calculada, com base, nos valores da composição bromatológica dos ingredientes e níveis nutricionais seguiram as recomendações de Rostagno et al. (2011) para as diferentes fases, com exceção dos níveis de $\mathrm{Ca}$ e Pd que foram reduzidos em alguns tratamentos conforme proposto pelo delineamento experimental. Água e ração foram disponibilizados ad libitum. A adição da enzima fitase nas dietas foi feita na forma on top, ou seja, sem considerar a valorização nutricional promovida pelo uso da enzima exógena. Nas dietas sem inclusão de fitase, utilizou-se caulim como material inerte em substituição ao produto enzimático. A fitase utilizada foi uma enzima de origem bacteriana derivada da Escherichi coli expressa em Pichia Pastoris, com realização da primeira hidrólise no carbono 6 da molécula de fitato com atividade enzimática declarada de $10.000 \mathrm{FTU} / \mathrm{kg}$. 
Tabela 2. Descrição dos tratamentos experimentais

\begin{tabular}{|c|c|c|c|c|c|}
\hline \multirow[t]{2}{*}{ Tratamento } & \multicolumn{4}{|c|}{ Níveis de Ca (\%) e Pd (\%) } & \multirow{2}{*}{$\begin{array}{l}\text { Inclusão da } \\
\text { Fitase } \\
\text { (FTU/Kg de } \\
\text { ração) }\end{array}$} \\
\hline & Pré Inicial & Inicial & Crescimento & Abate & \\
\hline T1 & Ca 0,92/Pd 0,47 & Ca 0,84/Pd 0,40 & $\mathrm{Ca} 0,76 / \mathrm{Pd} 0,35$ & $\mathrm{Ca} 0,66 / \mathrm{Pd} 0,31$ & 0 \\
\hline T2 & Ca 0,83/Pd 0,42 & Ca 0,76/Pd 0,36 & $\mathrm{Ca} 0,68 / \mathrm{Pd} 0,32$ & $\mathrm{Ca} 0,60 / \mathrm{Pd} 0,28$ & 0 \\
\hline T3 & Ca 0,74/Pd 0,38 & Ca 0,67/Pd 0,32 & $\mathrm{Ca} 0,61 / \mathrm{Pd} 0,28$ & Ca 0,53/Pd 0,25 & 0 \\
\hline T4 & $\mathrm{Ca} 0,92 / \mathrm{Pd} \mathrm{0,47}$ & $\mathrm{Ca} 0,84 / \mathrm{Pd} 0,40$ & $\mathrm{Ca} 0,76 / \mathrm{Pd} 0,35$ & $\mathrm{Ca} 0,66 / \mathrm{Pd} 0,31$ & 500 \\
\hline T5 & $\mathrm{Ca} 0,83 / \mathrm{Pd} 0,42$ & Ca 0,76/Pd 0,36 & $\mathrm{Ca} 0,68 / \mathrm{Pd} 0,32$ & $\mathrm{Ca} 0,60 / \mathrm{Pd} 0,28$ & 500 \\
\hline T6 & Ca 0,74/Pd 0,38 & $\mathrm{Ca} 0,67 / \mathrm{Pd} 0,32$ & $\mathrm{Ca} 0,61 / \mathrm{Pd} 0,28$ & $\mathrm{Ca} 0,53 / \mathrm{Pd} 0,25$ & 500 \\
\hline T7 & $\mathrm{Ca} 0,92 / \mathrm{Pd} 0,47$ & $\mathrm{Ca} 0,84 / \mathrm{Pd} 0,40$ & Ca $0,76 / \mathrm{Pd} 0,35$ & $\mathrm{Ca} 0,66 / \mathrm{Pd} 0,31$ & 1.000 \\
\hline T8 & $\mathrm{Ca} \mathrm{0,83/Pd} \mathrm{0,42}$ & Ca 0,76/Pd 0,36 & $\mathrm{Ca} 0,68 / \mathrm{Pd} 0,32$ & $\mathrm{Ca} 0,60 / \mathrm{Pd} 0,28$ & 1.000 \\
\hline T9 & Ca 0,74/Pd 0,38 & Ca 0,67/Pd 0,32 & $\mathrm{Ca} 0,61 / \mathrm{Pd} 0,28$ & $\mathrm{Ca} 0,53 / \mathrm{Pd} 0,25$ & 1.000 \\
\hline T10 & Ca 0,92/Pd 0,47 & Ca $0,84 / P d 0,40$ & $\mathrm{Ca} 0,76 / \mathrm{Pd} 0,35$ & $\mathrm{Ca} 0,66 / \mathrm{Pd} 0,31$ & 1.500 \\
\hline T11 & $\mathrm{Ca} 0,83 / \mathrm{Pd} 0,42$ & Ca 0,76/Pd 0,36 & $\mathrm{Ca} 0,68 / \mathrm{Pd} 0,32$ & $\mathrm{Ca} 0,60 / \mathrm{Pd} 0,28$ & 1.500 \\
\hline T12 & $\mathrm{Ca} 0,74 / \mathrm{Pd} 0,38$ & Ca 0,67/Pd 0,32 & $\mathrm{Ca} 0,61 / \mathrm{Pd} 0,28$ & $\mathrm{Ca} 0,53 / \mathrm{Pd} 0,25$ & 1.500 \\
\hline
\end{tabular}


Tabela 3. Composição percentual e níveis nutricionais calculados das dietas experimentais para frangos de corte na fase pré inicial (1-7 dias)

\begin{tabular}{|c|c|c|c|}
\hline \multirow[b]{2}{*}{ Ingredientes $(\mathrm{Kg})$} & \multicolumn{3}{|c|}{ Níveis de Ca e Pd (\%) } \\
\hline & Ca 0,92/Pd 0,47 & Ca $0,83 / P d 0,42$ & Ca 0,74/Pd 0,38 \\
\hline Milho moído & 55,305 & 56,016 & 56,727 \\
\hline Farelo de Soja $46 \%$ & 38,085 & 37,965 & 37,846 \\
\hline Óleo de Soja & 2,004 & 1,762 & 1,519 \\
\hline Cloreto de Colina $60 \%$ & 0,081 & 0,081 & 0,081 \\
\hline Sulfato de Cobre & 0,030 & 0,030 & 0,030 \\
\hline Calcário Calcítico & 1,178 & 1,064 & 0,950 \\
\hline Fosfato Monobicálcico & 1,692 & 1,455 & 1,219 \\
\hline Sal comum & 0,525 & 0,525 & 0,525 \\
\hline Inerte & $0,015 / 0,010 / 0,05 / 0,00$ & $0,015 / 0,010 / 0,05 / 0,00$ & $0,015 / 0,010 / 0,05 / 0,00$ \\
\hline L-Lisina HCL 78\% & 0,377 & 0,379 & 0,381 \\
\hline DL-Metionina 99\% & 0,385 & 0,384 & 0,384 \\
\hline L-Treonina 98\% & 0,171 & 0,171 & 0,171 \\
\hline Fitase & $0,00 / 0,005 / 0,010 / 0,015$ & $0,00 / 0,005 / 0,010 / 0,015$ & $0,00 / 0,005 / 0,010 / 0,015$ \\
\hline Antimicrobiano $^{1}$ & 0,050 & 0,050 & 0,050 \\
\hline Anticoccidiano $^{2}$ & 0,003 & 0,003 & 0,003 \\
\hline Premix Vitamínico Mineral $^{3}$ & 0,100 & 0,100 & 0,100 \\
\hline Nutrientes & & Composição Calculada & \\
\hline Proteína Bruta (\%) & 22,40 & 22,40 & 22,40 \\
\hline $\mathrm{P}$ disp. (\%) & 0,47 & 0,42 & 0,38 \\
\hline Cálcio (\%) & 0,92 & 0,83 & 0,74 \\
\hline Lisina dig. (\%) & 1,32 & 1,32 & 1,32 \\
\hline Met+Cis dig. (\%) & 0,95 & 0,95 & 0,95 \\
\hline $\mathrm{EM}(\mathrm{kcal} / \mathrm{Kg})$ & 2960 & 2960 & 2960 \\
\hline
\end{tabular}

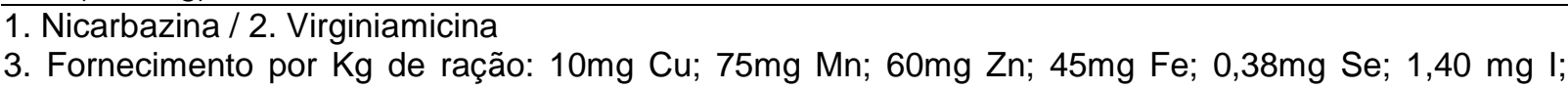
$10.000 \mathrm{UI}$ Vit A; 3.000UI Vit D3; 25mg Vit E; $1,5 \mathrm{mg}$ Vit B1; 6,5mg Vit B2; 3mg Vit B6; 20mcg Vit B12; $60 \mathrm{mcg}$ Biotina; $2 \mathrm{mg}$ Vit K3; 35mg Niacina; 1,25mg Ácido Fólico; 12mg Ácido Pantotênico. 
Tabela 4. Composição percentual e níveis nutricionais calculados das dietas experimentais para frangos de corte na fase inicial (8-21 dias)

\begin{tabular}{|c|c|c|c|}
\hline \multirow[b]{2}{*}{ Ingredientes $(\mathrm{Kg})$} & \multicolumn{3}{|c|}{ Níveis de Ca e Pd (\%) } \\
\hline & Ca 0,84/Pd 0,40 & Ca 0,76/Pd 0,36 & Ca 0,67/Pd 0,32 \\
\hline Milho Moído & 57,688 & 58,324 & 58,962 \\
\hline Farelo de Soja $46 \%$ & 35,307 & 35,200 & 35,093 \\
\hline Óleo de Soja & 2,900 & 2,683 & 2,465 \\
\hline Cloreto de Colina $60 \%$ & 0,080 & 0,080 & 0,080 \\
\hline Sulfato de Cobre & 0,030 & 0,030 & 0,030 \\
\hline Calcário Calcítico & 1,169 & 1,057 & 0,945 \\
\hline Fosfato Monobicálcico & 1,368 & 1,166 & 0,964 \\
\hline Sal comum & 0,500 & 0,500 & 0,500 \\
\hline Inerte & 0,015/0,010/0,05/0,00 & 0,015/0,010/0,05/0,00 & $0,015 / 0,010 / 0,05 / 0,00$ \\
\hline L-Lisina HCL 78\% & 0,321 & 0,323 & 0,325 \\
\hline DL-Metionina 99\% & 0,332 & 0,331 & 0,330 \\
\hline L-Treonina 98\% & 0,138 & 0,138 & 0,138 \\
\hline Fitase & $0,00 / 0,005 / 0,010 / 0,015$ & $0,00 / 0,005 / 0,010 / 0,015$ & $0,00 / 0,005 / 0,010 / 0,015$ \\
\hline Antimicrobiano $^{1}$ & 0,050 & 0,050 & 0,050 \\
\hline Anticoccidiano $^{2}$ & 0,003 & 0,003 & 0,003 \\
\hline Premix Vitamínico Mineral ${ }^{3}$ & 0,100 & 0,100 & 0,100 \\
\hline Nutrientes & & Composição Calculada & \\
\hline Proteína Bruta (\%) & 21,20 & 21,20 & 21,20 \\
\hline $\mathrm{P}$ disp. (\%) & 0,40 & 0,36 & 0,32 \\
\hline Cálcio (\%) & 0,84 & 0,76 & 0,67 \\
\hline Lisina dig. (\%) & 1,22 & 1,22 & 1,22 \\
\hline Met+Cis dig. (\%) & 0,88 & 0,88 & 0,88 \\
\hline EM $(\mathrm{kcal} / \mathrm{Kg})$ & 3050 & 3050 & 3050 \\
\hline
\end{tabular}

1.Robenidina / 2.Virginiamicina

3. Fornecimento por $\mathrm{Kg}$ de ração: $10 \mathrm{mg} \mathrm{Cu} ; 75 \mathrm{mg} \mathrm{Mn;} 60 \mathrm{mg} \mathrm{Zn;} 45 \mathrm{mg} \mathrm{Fe} ; 0,38 \mathrm{mg} \mathrm{Se} ; 1,40 \mathrm{mg} \mathrm{I}$; 10.000UI Vit A; 3.000UI Vit D3; 25mg Vit E; 1,5mg Vit B1; 6,5mg Vit B2; 3mg Vit B6; 20mcg Vit B12; $60 \mathrm{mcg}$ Biotina; $2 \mathrm{mg}$ Vit K3; 35mg Niacina; 1,25mg Ácido Fólico; 12mg Ácido Pantotênico. 
Tabela 5. Composição percentual e níveis nutricionais calculados das dietas experimentais para frangos de corte na fase de crescimento (22-35 dias)

\begin{tabular}{|c|c|c|c|}
\hline \multirow[b]{2}{*}{ Ingredientes $(\mathrm{Kg})$} & \multicolumn{3}{|c|}{ Níveis de Ca e Pd (\%) } \\
\hline & Ca 0,76/Pd 0,35 & Ca 0,68/Pd 0,32 & Ca 0,61/Pd 0,28 \\
\hline Milho Moído & 60,552 & 61,123 & 61,694 \\
\hline Farelo de Soja $46 \%$ & 31,882 & 31,786 & 31,690 \\
\hline Óleo de Soja & 3,851 & 3,656 & 3,462 \\
\hline Cloreto de Colina $60 \%$ & 0,070 & 0,070 & 0,070 \\
\hline Sulfato de Cobre & 0,028 & 0,028 & 0,028 \\
\hline Calcário Calcítico & 1,058 & 0,954 & 0,851 \\
\hline Fosfato Monobicálcico & 1,161 & 0,983 & 0,805 \\
\hline Sal comum & 0,475 & 0,475 & 0,475 \\
\hline Inerte & 0,015/0,010/0,05/0,00 & 0,015/0,010/0,05/0,00 & $0,015 / 0,010 / 0,05 / 0,00$ \\
\hline L-Lisina HCL 78\% & 0,312 & 0,313 & 0,315 \\
\hline DL-Metionina 99\% & 0,312 & 0,311 & 0,310 \\
\hline L-Treonina 98\% & 0,127 & 0,127 & 0,128 \\
\hline Fitase & $0,00 / 0,005 / 0,010 / 0,015$ & $0,00 / 0,005 / 0,010 / 0,015$ & $0,00 / 0,005 / 0,010 / 0,015$ \\
\hline Antimicrobiano $^{1}$ & 0,055 & 0,055 & 0,055 \\
\hline Anticoccidiano $^{2}$ & 0,003 & 0,003 & 0,003 \\
\hline Premix Vitamínico Mineral ${ }^{3}$ & 0,100 & 0,100 & 0,100 \\
\hline Nutrientes & & Composição Calculada & \\
\hline Proteína Bruta (\%) & 19,80 & 19,80 & 19,80 \\
\hline $\mathrm{P}$ disp. (\%) & 0,35 & 0,32 & 0,28 \\
\hline Cálcio (\%) & 0,76 & 0,68 & 0,61 \\
\hline Lisina dig. (\%) & 1,13 & 1,13 & 1,13 \\
\hline Met+Cis dig. (\%) & 0,83 & 0,83 & 0,83 \\
\hline EM $(\mathrm{kcal} / \mathrm{Kg})$ & 3150 & 3150 & 3150 \\
\hline
\end{tabular}

1.Salinomicina / 2. Virginiamicina

3. Fornecimento por Kg de ração: $10 \mathrm{mg} \mathrm{Cu} ; 70 \mathrm{mg} \mathrm{Mn} ; 60 \mathrm{mg} \mathrm{Zn} ; 40 \mathrm{mg} \mathrm{Fe} ; 0,33 \mathrm{mg} \mathrm{Se} ; 1,10 \mathrm{mg} \mathrm{I} ; 8.000 \mathrm{UI}$ Vit A; 2.500UI Vit D3; 17,5mg Vit E; 1 mg Vit B1; 4mg Vit B2; 2mg Vit B6; 15mcg Vit B12; 36mcg Biotina; $1 \mathrm{mg}$ Vit K3; 30mg Niacina; $1 \mathrm{mg}$ Ácido Fólico; 9mg Ácido Pantotênico. 
Tabela 6. Composição percentual e níveis nutricionais calculados das dietas experimentais para frangos de corte na fase de abate (36-42 dias)

\begin{tabular}{|c|c|c|c|}
\hline \multirow{2}{*}{ Ingredientes (Kg) } & \multicolumn{3}{|c|}{ Níveis de Ca e Pd (\%) } \\
\hline & Ca 0,66/Pd 0,31 & Ca $0,60 / P d ~ 0,28$ & Ca 0,53/Pd 0,25 \\
\hline Milho Moído & 64,687 & 65,187 & 65,686 \\
\hline Farelo de Soja $46 \%$ & 28,167 & 28,083 & 27,999 \\
\hline Óleo de Soja & 3,808 & 3,638 & 3,467 \\
\hline Cloreto de Colina $60 \%$ & 0,059 & 0,059 & 0,059 \\
\hline Sulfato de Cobre & 0,021 & 0,021 & 0,021 \\
\hline Calcário Calcítico & 0,971 & 0,880 & 0,790 \\
\hline Fosfato Monobicálcico & 0,962 & 0,806 & 0,651 \\
\hline Sal comum & 0,464 & 0,464 & 0,464 \\
\hline Inerte & $0,015 / 0,010 / 0,05 / 0,00$ & $0,015 / 0,010 / 0,05 / 0,00$ & $0,015 / 0,010 / 0,05 / 0,00$ \\
\hline L-Lisina HCL 78\% & 0,327 & 0,329 & 0,330 \\
\hline DL-Metionina 99\% & 0,289 & 0,288 & 0,288 \\
\hline L-Treonina 98\% & 0,128 & 0,128 & 0,128 \\
\hline Fitase & $0,00 / 0,005 / 0,010 / 0,015$ & $0,00 / 0,005 / 0,010 / 0,015$ & $0,00 / 0,005 / 0,010 / 0,015$ \\
\hline Anticoccidiano $^{1}$ & 0,003 & 0,003 & 0,003 \\
\hline Premix Vitamínico Mineral² & 0,100 & 0,100 & 0,100 \\
\hline Nutrientes & & Composição Calculada & \\
\hline Proteína Bruta (\%) & 18,40 & 18,40 & 18,40 \\
\hline $\mathrm{P}$ disp. (\%) & 0,31 & 0,28 & 0,25 \\
\hline Cálcio (\%) & 0,66 & 0,60 & 0,53 \\
\hline Lisina dig. (\%) & 1,06 & 1,06 & 1,06 \\
\hline Met+Cis dig. (\%) & 0,77 & 0,77 & 0,77 \\
\hline $\mathrm{EM}(\mathrm{kcal} / \mathrm{Kg})$ & 3200 & 3200 & 3200 \\
\hline
\end{tabular}

1.Virginiamicina

2. Fornecimento por Kg de ração: $8 \mathrm{mg} \mathrm{Cu} ; 52 \mathrm{mg} \mathrm{Mn;} 45 \mathrm{mg} \mathrm{Zn} ; 30 \mathrm{mg} \mathrm{Fe} ; 0,25 \mathrm{mg}$ Se; 0,9mg I; $5.500 \mathrm{UI}$ Vit A; 1.100Ul Vit D3; 12,5mg Vit E; 0,5mg Vit B1;3mg Vit B2; 0,5mg Vit B6; 6mcg Vit B12; 25mcg Biotina; 0,8mg Vit K3; 15mg Niacina; 0,3mg Ácido Fólico; 5mg Ácido Pantotênico. 


\subsection{Avaliação do desempenho}

Os dados de desempenho foram obtidos aos 7, 21 e 42 dias de idade, sendo: peso corporal peso das aves; ganho de peso (diferença entre o peso ao final e inicial de cada período de criação); consumo de ração (diferença entre o total de ração fornecida e as sobras de cada período, baseado no número médio de aves); conversão alimentar (razão entre o total de ração consumida no período e o ganho de peso, corrigido pelo peso das aves mortas), mortalidade (anotada diariamente e expressa em percentual, pela relação entre o número de aves mortas no período e o número inicial de aves) e fator de eficiência produtiva (calculado aos 42 dias de idade pela multiplicação entre o ganho de peso médio diário e a viabilidade, divididos pela conversão alimentar, e então multiplicados por 100).

\subsection{Rendimento de carcaça}

Ao final do experimento, com 43 dias de idade, para avaliação do rendimento de carcaça e cortes, as aves foram abatidas no Abatedouro Escola da Universidade de São Paulo, campus Fernando Costa. Foram selecionadas duas aves de cada repetição, totalizando 192 aves. As aves foram identificadas com anilha, pesadas individualmente e após jejum alimentar de oito horas para esvaziamento do trato gastrintestinal, abatidas seguindo a rotina convencional do abatedouro.

Após a insensibilização (eletronarcose), sangria, escalda, depenação, evisceração manual e retirada da cabeça e pescoço, as carcaças foram resfriadas em chiller. Então, procedeu-se a pesagem da carcaça eviscerada fria sem cabeça, pescoço e pés e, na sequência dos cortes, a pesagem das partes: peito (desossado e sem pele), pernas (coxa e sobrecoxa) e asas.

Na determinação do rendimento de carcaça, foi considerado o peso da carcaça eviscerada (sem cabeça, pescoço e pés) em relação ao peso vivo da ave após o jejum, antes do abate. Foi realizado, também, a relação percentual do peso do peito (desossado e sem pele), pernas (coxa e sobrecoxa) e asas em relação à carcaça eviscerada sem cabeça, pescoço e pés. 


\subsection{Qualidade óssea}

A tíbia direita de uma das aves que foram abatidas para avaliação de rendimento de carcaça foi coletada para o estudo da qualidade óssea. As amostras foram imediatamente congeladas para posterior análise.

\subsubsection{Conteúdo e densidade mineral óssea}

As tíbias foram dessecadas e submetidas à análise em densitômetro de dupla emissão de raios - X (DXA) (Figura 2, modelo DPX-Alpha, Lunar ${ }^{\circledR}$ ) com software especial para pequenos animais, em que foram registrados o conteúdo mineral ósseo - CMO (g) e a densidade mineral óssea - DMO $\left(\mathrm{g} / \mathrm{cm}^{2}\right)$ no Laboratório de Densitometria Óssea do Departamento de Morfologia e Fisiologia Animal da Universidade Estadual Paulista campus Jaboticabal.

Figura 2 - Densitômetro modelo DPX-Alpha, Lunar®

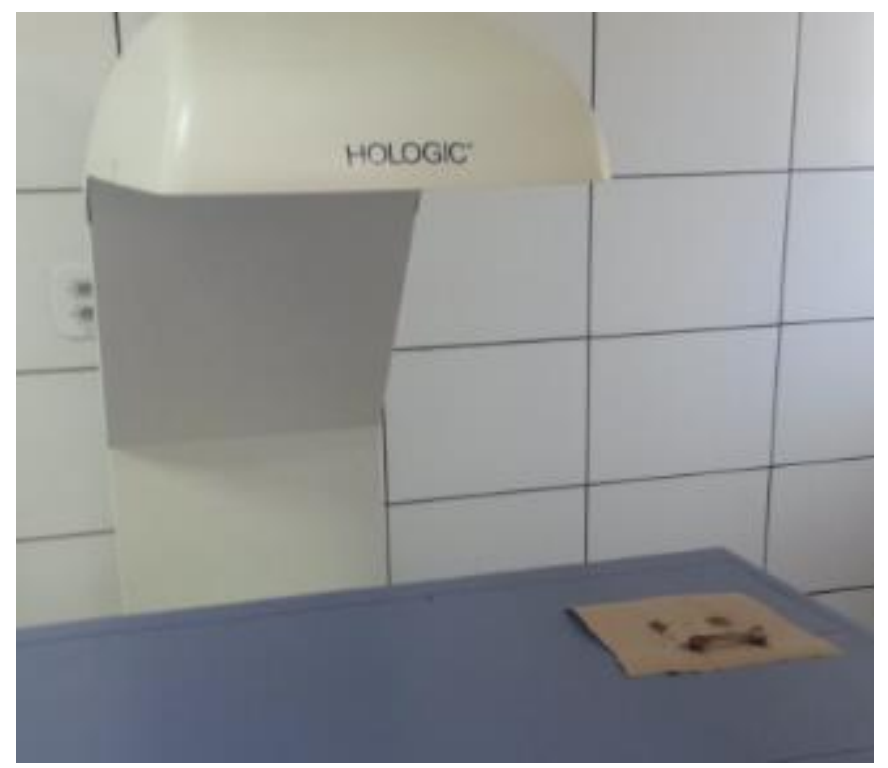

Fonte: (MARANGONI, R.S., 2017)

\subsubsection{Resistência Óssea}

Após a avaliação da densidade, as tíbias foram utilizadas na determinação da resistência óssea (Figura 3). Para tanto, foi utilizado o equipamento universal de ensaio 
EMIC $\circledast$, modelo DL 3000, com carga aplicada à velocidade de $54 \mathrm{~mm} / \mathrm{min}$ e a célula de carga de $1 \mathrm{kN}$ (pertence ao Laboratório de construções \& Ambiência da Universidade de São Paulo, campus Fernando Costa).

$\mathrm{Na}$ análise foi determinada a força máxima admitida pela tíbia e sua rigidez, variáveis que expressam a resistência óssea. No ensaio de flexão em três pontos, as tíbias ficaram apoiadas em aparato que as mantiveram na posição horizontal, com distância de vão de apoio em 3/4 do tamanho do osso, e a força foi aplicada da meia distância de vão.

Os resultados dos ensaios foram registrados pelo software do equipamento na forma gráfica, o qual gera a curva: carga $x$ deformação. Da análise das curvas obtevese a seguinte propriedade biomecânica: força máxima $(\mathrm{N})$ que corresponde a maior carga suportada pela amostra (tíbia) durante o ensaio.

Figura 3 - Máquina universal de ensaio $\mathrm{EMIC}^{\circledR}$, modelo $\mathrm{DL} 3000$, em ensaio mecânico de flexão de três pontos da tíbia direita

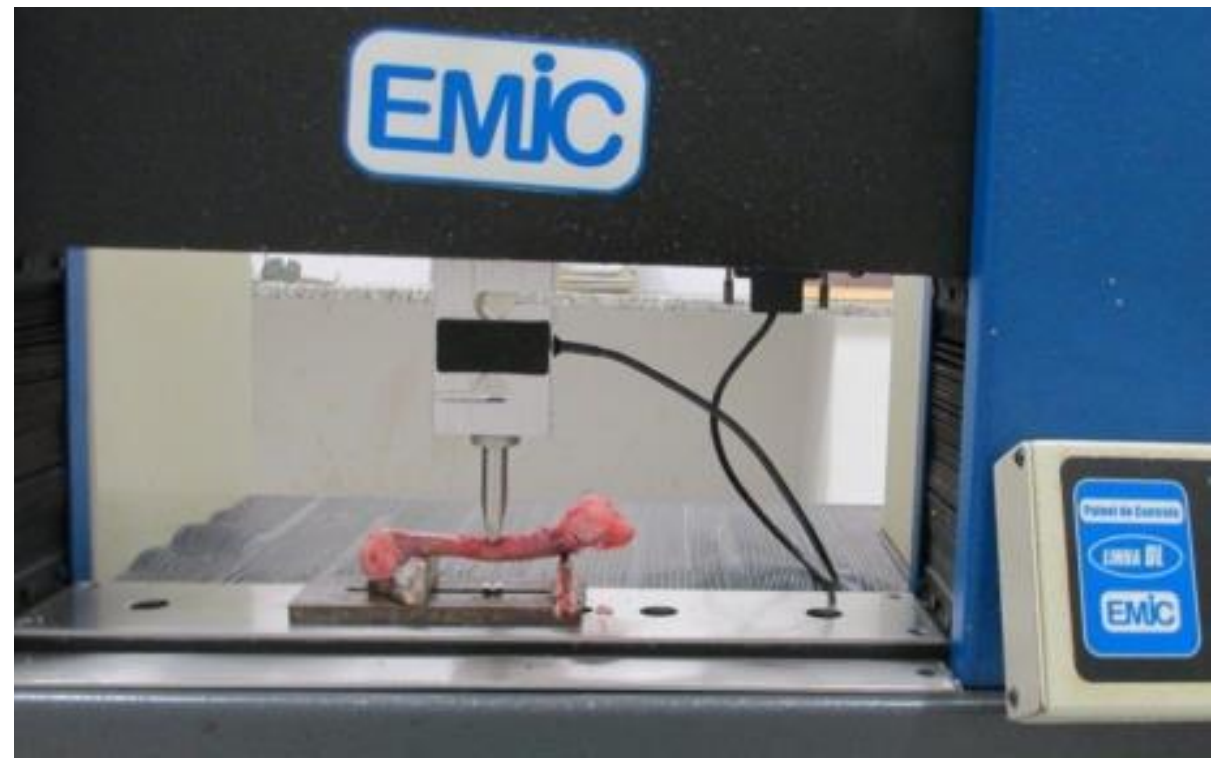

Fonte: (MARANGONI, R. S., 2017)

\subsection{Análises estatísticas}

Os resultados foram analisados por meio do programam computacional Statistical Analisis System 9.3 (SAS, 2005), sendo anteriormente verificada a normalidade dos resíduos estudentizados pelo Teste de Shapiro-Wilk (PROC GLM) e as variâncias comparadas pelo Teste de Levene. 
Os dados originais foram submetidos à análise de variância, utilizando-se o Proc Mixed. Para avaliação da influência dos resultados dos níveis de $\mathrm{Ca}$ e $\mathrm{Pd}$ e das diferentes dosagens de fitase, foram realizados os desdobramentos dos níveis dentro de cada nível de fitase (por meio de análises de regressão) bem como, níveis de Ca e Pd dentro de cada nível de fitase (por meio do teste de Tukey) para todas as variáveis analisadas.

\section{RESULTADOS E DISCUSSÃO}

\subsection{Desempenho Animal}

Os resultados de desempenho nos períodos de 1 a 7 dias, 1 a 21 dias e 1 a 42 dias são apresentados na Tabela 7, de acordo com os diferentes níveis de $\mathrm{Ca}$ e Pd (80\%, 90\% e 100\% da recomendação) e fitase (0, 500, 1000 e $1500 \mathrm{FTU} / \mathrm{Kg}$ de ração). No período de 1 a 21 dias, houve interação entre o nível de Ca e Pd na dieta e adição de fitase $(P=0.002)$. Nas dietas contendo 80 e $90 \%$ de redução, o ganho de peso aumentou $(P<0.001)$ em 0,000049 e $0,000065 \mathrm{~kg} / \mathrm{FTU}$ de fitase, respectivamente, enquanto que na dieta contendo $100 \%$ da recomendação de $\mathrm{Ca}$ e $\mathrm{Pd}$, a adição da enzima não afetou o ganho de peso ( $P=0.092)$. (Gráfico 1)

Gráfico 1. Efeito dos níveis de Ca e Pd nas dietas e a adição de diferentes níveis de fitase sobre o ganho de peso (Kg/dia)

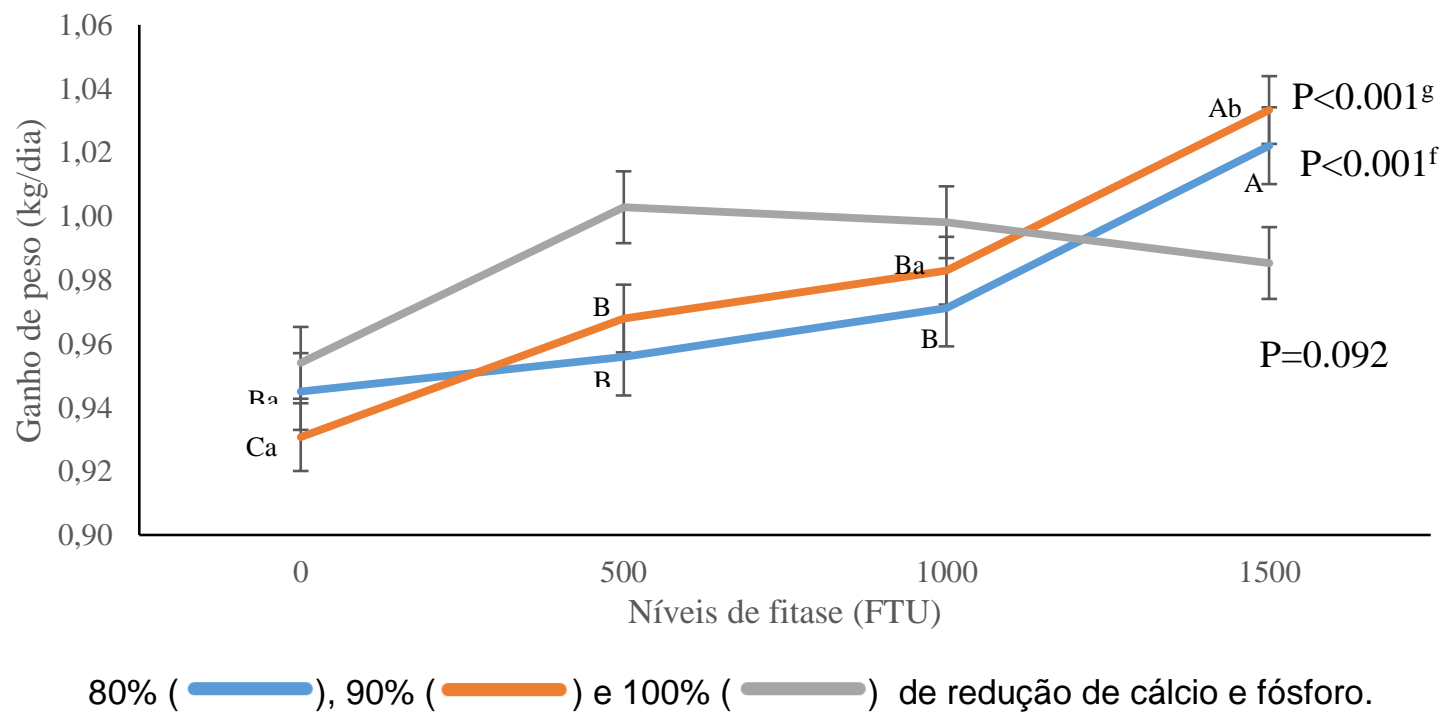

fGanho de peso (kg/ave; TRAT $=80)=0,9365( \pm 0,01047)+0,000049( \pm 0,000011)$ enzima(FTU)

9 Ganho de peso $(\mathrm{kg} / \mathrm{ave}$; TRAT $=90)=0,9303( \pm 0,009236)+0,000065( \pm 9,87 \mathrm{E}-06)$ enzima (FTU) letras maiúsculas na mesma linha e minúsculas na mesma coluna diferem estatisticamente pelo teste $F$ $(0,05)$ 
Os níveis de fitase influenciaram significativamente o ganho de peso médio e a conversão alimentar das aves. Com o incremento dos níveis de fitase, houve aumento linear para ganho de peso médio, aos 7 e 21 dias, e houve redução linear na conversão alimentar aos 21 dias. Considerando o período de 1 a 42 dias, o ganho de peso médio foi significativamente afetado pelos diferentes níveis de inclusão de fitase, sendo que a dieta sem inclusão da enzima proporcionou resultados inferiores quando comparados aos obtidos com o uso das dietas contendo 500 e 1500 FTU/Kg, porém se assemelhando a dieta contendo $1000 \mathrm{FTU} / \mathrm{Kg}$ de ração. O mesmo foi observado com a variável conversão alimentar média, ou seja, dietas contendo 500 e 1500 FTU/Kg de fitase apresentaram resultados melhores em relação a dieta sem inclusão da enzima. A dieta contendo $1000 \mathrm{FTU} / \mathrm{Kg}$ de ração não diferiu significativamente da dieta sem inclusão da fitase.

O índice de eficiência produtiva apresentou melhores resultados em dietas contendo 500 e $1500 \mathrm{FTU} / \mathrm{Kg}$ de ração da enzima fitase $(P<0,041)$, os resultados obtidos para esta característica já era esperado, em razão das diferenças entre os tratamentos que ocorreram para ganho de peso e conversão alimentar.

Os níveis de $\mathrm{Ca}$ e Pd afetaram o desempenho das aves no período de 1 a 7 dias, sendo que o uso da dieta contendo $100 \%$ e $90 \%$ da recomendação dos níveis de $\mathrm{Ca}$ e Pd, não diferiram significativamente entre si, propiciaram os melhores resultados para ganho de peso médio e conversão alimentar quando comparados com dietas contendo 80\% da recomendação de Ca e Pd. Em um trabalho semelhante, Camden et al. (2001) encontraram resultados com diferenças significativas quando estudaram a influência de vários níveis de fitase microbiana (0,250, 500 e $1000 \mathrm{U} / \mathrm{kg}$ de dieta) no desempenho de frangos de corte na fase inicial, recebendo dietas à base de milho e farelo de soja com níveis de Pd e Ca recomendados pelo NRC (1994) e níveis reduzidos de Ca (8,0g/kg de dieta) e $\mathrm{Pd}(3,0 \mathrm{~g} / \mathrm{kg}$ de dieta). A redução do nível de $\mathrm{Pd}$ da dieta afetou negativamente o desempenho das aves e a adição de 500 FTU de fitase/kg melhorou o ganho de peso e a conversão alimentar.

O consumo médio de ração não diferiu significativamente quanto aos diferentes níveis de fitase e redução dos níveis de Ca e $\mathrm{Pd}$, o que está de acordo com Costa et al. (2007), que também não verificaram efeito da fitase no consumo de rações formuladas à base de milho e farelo de soja com $23 \%$ de proteína bruta (fase pré-inicial - 1 a 7 dias de idade) e $21 \%$ de proteína bruta (fase inicial - 8 a 21 dias de idade) nas 
dietas. Em relação à redução dos níveis de $\mathrm{Ca}$ e $\mathrm{Pd}$, o resultado do presente trabalho difere de outros estudos como os resultados apresentados por Edwards Junior (1993), Quian et al. (1997) e Sebastian et al. (1997), os quais notaram redução no consumo de ração de frangos ao aumentarem o nível de Ca na ração.

Há resultados bastante controversos aos apresentados nesse trabalho e na literatura disponível como por exemplo quando os autores Demyr \& Sekerodlu (2002) constataram que a suplementação de fitase não teve efeito significativo na conversão alimentar para as aves que foram alimentadas com dietas com níveis adequados ou deficientes de P, Ca e PB. Embora, segundo esses autores, a dieta com teores reduzidos de $\mathrm{P}, \mathrm{Ca}$ e inclusão de fitase tenham significativamente aumentado o ganho de peso e o consumo de ração, e os frangos alimentados com as dietas com baixo $\mathrm{Ca}$ e $\mathrm{P}$ ou baixo $\mathrm{Ca}, \mathrm{P}, \mathrm{PB}$ e inclusão de fitase consumiram mais do que aquelas alimentadas com a dieta basal.

Segundo Schoulten et al. (2003), a exigência de cálcio para frangos, em rações com baixo $\mathrm{P}$ e suplementadas com fitase, é inferior à exigência normalmente recomendada em tabelas de exigências nutricionais, indicando que a redução do nível de cálcio da ração deve ser proporcional à redução do nível de $P$, em virtude da utilização da fitase, mantendo-se, dessa forma, uma relação de Ca:P adequada. Assim, no presente estudo, comparado à ração controle, nota-se ser possível reduzir os níveis de $\mathrm{Ca}$ e Pd sem afetar os parâmetros de desempenho das aves. Ainda, as reduções dos níveis de $\mathrm{Ca}$ e $\mathrm{Pd}$ foram feitas na mesma proporção entre os dois minerais, mantendo a relação recomendada entre os mesmos. Isso pode ter contribuído para os parâmetros de desempenho encontrados.

Uma série de fatores, incluindo a fonte de fitase (tipo, origem, teor de fitato), e as características nutricionais (processamento, níveis de vitamina D3, relação Ca:P) pode ter influenciado no desempenho das aves. A liberação de minerais presentes no complexo fitato mineral, a utilização do inositol (produto final da desfosforalização do ácido fítico) pelos animais e o aumento da digestibilidade do amido e da disponibilidade da proteína foram descritos por Sebastian et al. (1996) como fatores que poderiam melhorar o desempenho das aves alimentadas com dietas suplementadas com fitase conforme os resultados apresentados no presente trabalho. 
Tabela 7. Níveis de Ca e Pd e uso de diferentes níveis de inclusão da enzima fitase em dietas para frangos de corte sobre o desempenho.

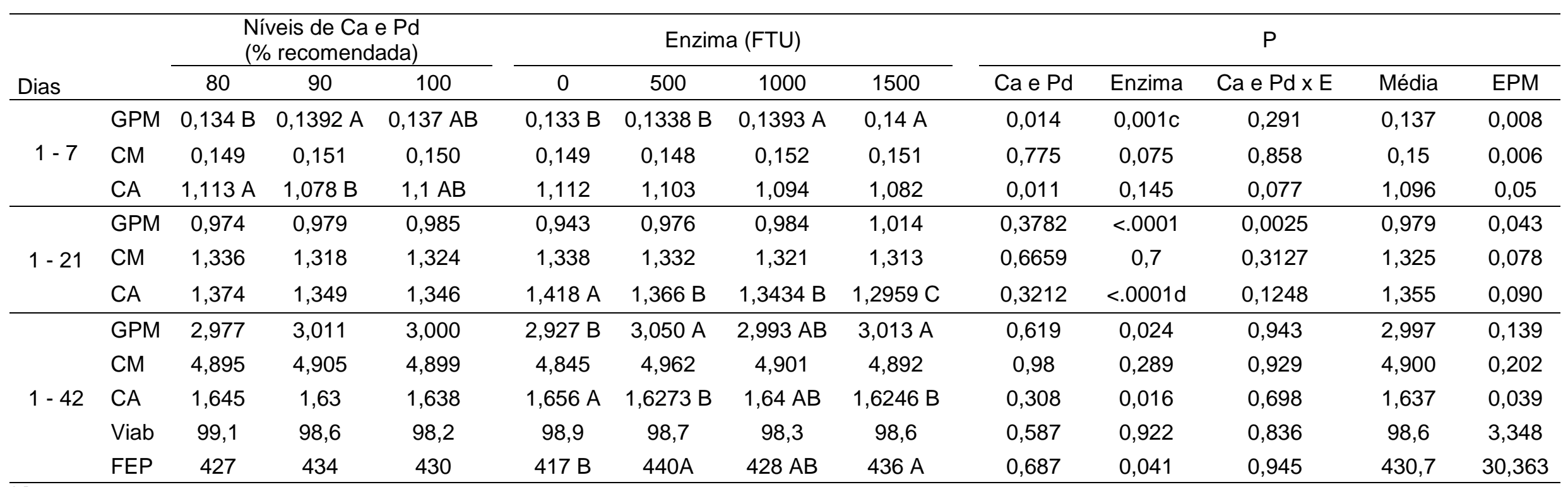

A,BMédias seguidas por letras maiúsculas na mesma linha diferem estatisticamente pelo teste $F(0,05)$

GMP, ganho de peso médio (g); CM, consumo alimentar médio (g); CA, conversão alimentar (g/g); Viab, viabilidade (\%); FEP, fator de produção.

c $Y=0,1335( \pm 0,00123)+4,64 \mathrm{E}-06( \pm 1,3 \mathrm{E}-06) \times$ enzima; linear

$d Y=1,4133( \pm 0,01357)-0,00008( \pm 0,000015) x$ enzima; linear 
Esses resultados estão de acordo, em parte, com os valores obtidos por Viveros et al. (2002), em que os autores verificaram que a redução no nível de Pd de 0,37 para 0,14\%, na fase de 22 a 42 dias de idade, acarretou redução no ganho de peso e, ao utilizar a enzima fitase, ocorreu aumento significativo no ganho de peso.

\subsection{Rendimento de carcaça}

Os resultados das variáveis referentes ao rendimento de carcaça estão apresentados na Tabela 8. Não houve interação significativa entre os níveis de Ca e $P d$ e a fitase. Além disto, não foram observados efeitos significativos sobre as variáveis de rendimento de carcaça, rendimento de peito, pernas e asas.

Esses resultados concordam com os achados de Ceylan et al (2012) em que diferenças não significativas no rendimento e na composição de carcaça de frangos suplementados com fitase (500 FTU/kg) e baixos níveis de $P$ total $(0,13 \%)$ também foram observadas. Por outro lado, os achados do presente estudo diferem dos obtidos por Ahmad et al. (2004) em que observaram que a suplementação com 1.000 FTU promoveu o aumento dos rendimentos de peito, fígado e coração e reduziu a gordura abdominal.

Baradaran et al. (2013) mostraram que a inclusão de fitase em $1.000 \mathrm{FTU} / \mathrm{kg}$ e a redução dos niveis de $\mathrm{P}$ não fítico (4 para 2,3 g/kg) na fase de crescimento aumentaram o rendimento de carcaça de frangos sem afetar o rendimento de peito de frangos com uma tendência de declínio da gordura abdominal de frangos.

Oliveira et al. (2009), Gomide et al. (2011) e Silva et al. (2012) avaliaram diferentes níveis de fitase, em dietas com Pd reduzido, e não observaram efeito sobre essas variáveis, nem mesmo sobre o rendimento de peito. Contudo, Ahmad et al. (2004) constataram que a suplementação de $1000 \mathrm{FTU} / \mathrm{kg}$ da dieta promoveu aumento no rendimento de peito e redução na gordura abdominal.

Kornegay e Debow (1996) afirmaram que o teor de $\mathrm{P}$ ou a presença de fitase não são relevantes para a qualidade da carcaça de frangos. Chen e Moran Jr (1995) mostraram que as diferenças na qualidade da carcaça de frangos alimentados com quantidade ideal ou baixo Pd não são perceptíveis ao longo do desenvolvimento da ave, no entanto, as diferenças podem se tornar visíveis durante o processamento dos 
cortes para obter a carcaça desossada. Perdas significativas podem ocorrer durante 0 processamento da carne devido a frequente quebra de ossos de frangos alimentados com deficientes níveis de $\mathrm{P}$. Torna-se essencial manter níveis de $\mathrm{Ca}$ e $\mathrm{P}$ adequados durante todo o período de crescimento das aves pois deficientes níveis na fase inicial podem inibir o crescimento e contribuir para defeitos na carcaça.

No presente estudo, é provável que tenha ocorrido uma melhora na digestibilidade de $\mathrm{Pd}$ que promoveu um aumento no aproveitamento do mineral. Isto porque não foram observados relatos de fragilidade óssea durante o processamento dos cortes no abate e, consequentemente não houve perdas significativas no processamento da carne. Mesmo nas dietas com redução dos níveis de $\mathrm{Ca}$ e Pd os resultados de desempenho foram semelhantes aos demais tratamento o que poderia justificar a ausência de efeitos significativos para as variáveis de rendimento de carcaça.

\subsection{Qualidade óssea}

Os resultados das variáveis referentes ao conteúdo e densidade mineral óssea e a força máxima força máxima admitida pela tíbia estão apresentados na Tabela 9.

Fukayama et al. (2008) na avaliação da composição em matéria mineral de Ca e $\mathrm{P}$ dos ossos das tíbias, observou-se que esses elementos foram depositados em maior quantidade nos ossos das aves que receberam dietas suplementadas com fitase, agregando uma melhora na resistência óssea.

Powell et al. (2008) observaram que frangos suplementados com dietas contendo $500 \mathrm{FTU} / \mathrm{kg}$, baixos níveis de $\mathrm{Pd}(0,20 \%)$ e diferentes concentrações de cálcio $(0,67 \% ; 1,00 \%$ e $1,33 \%)$ aumentou a resistência óssea, peso dos ossos e a porcentagem de cinzas na tíbia.

Fukayama et al. (2008) na avaliação da composição em matéria mineral de Ca e $\mathrm{P}$ dos ossos das tíbias, observou-se que esses elementos foram depositados em maior quantidade nos ossos das aves que receberam dietas suplementadas com fitase, agregando uma melhora na resistência óssea.

Powell et al. (2008) observaram que frangos suplementados com dietas contendo $500 \mathrm{FTU} / \mathrm{kg}$, baixos níveis de $\mathrm{Pd}(0,20 \%)$ e diferentes concentrações de cálcio $(0,67 \% ; 1,00 \%$ e $1,33 \%)$ aumentou a resistência óssea, peso dos ossos e a porcentagem de cinzas na tíbia. 
Tabela 8. Níveis de $\mathrm{Ca}$ e Pd e uso de diferentes níveis de inclusão da enzima fitase em dietas para frangos de corte sobre o rendimento de carcaça. Níveis de $\mathrm{Ca}$ e $\mathrm{Pd}$

\begin{tabular}{|c|c|c|c|c|c|c|c|c|c|c|c|c|}
\hline \multirow[b]{2}{*}{ Variáveis } & \multicolumn{3}{|c|}{$\begin{array}{l}\text { Níveis de Ca e Pd } \\
(\%)\end{array}$} & \multicolumn{4}{|c|}{ Enzima (FTU) } & \multicolumn{5}{|c|}{$P$} \\
\hline & 80 & 90 & 100 & 0 & 500 & 1000 & 1500 & Média & EPM & $\mathrm{Ca}$ e Pd & Enzima & $\begin{array}{l}\text { Ca e Pd x } \\
\text { Enz }\end{array}$ \\
\hline R_CARC & 0,71 & 0,708 & 0,712 & 0,706 & 0,708 & 0,709 & 0,717 & 0,71 & 0,016 & 0,670 & 0,103 & 0,152 \\
\hline R_PEITO & 0,332 & 0,335 & 0,337 & 0,335 & 0,339 & 0,33 & 0,335 & 0,335 & 0,015 & 0,529 & 0,303 & 0,952 \\
\hline R_PERNA & 0,326 & 0,324 & 0,323 & 0,325 & 0,323 & 0,327 & 0,323 & 0,324 & 0,010 & 0,494 & 0,422 & 0,571 \\
\hline R_ASA & 0,11 & 0,109 & 0,109 & 0,109 & 0,110 & 0,109 & 0,109 & 0,109 & 0,004 & 0,287 & 0,437 & 0,357 \\
\hline
\end{tabular}

Médias seguidas por letras maiúsculas na mesma linha diferem estatisticamente pelo teste $F(0,05)$

R_CARC, rendimento de carcaça (\%); R_PEITO, rendimento de peito (\%); R_PERNA, rendimento de perna (\%); R_ASA, rendimento de asa (\%)

Tabela 9. Níveis de Ca e Pd e uso de diferentes níveis de inclusão da enzima fitase em dietas para frangos de corte sobre a qualidade óssea.

\begin{tabular}{|c|c|c|c|c|c|c|c|c|c|c|c|c|}
\hline \multirow[b]{2}{*}{ Variáveis } & \multicolumn{3}{|c|}{ Níveis de Ca e Pd (\%) } & \multicolumn{4}{|c|}{ Enzima (FTU) } & \multicolumn{5}{|c|}{$P$} \\
\hline & 80 & 90 & 100 & 0 & 500 & 1000 & 1500 & $\begin{array}{c}\mathrm{Ca} \mathrm{e} \\
\mathrm{Pd}\end{array}$ & Enzima & $\begin{array}{c}\text { Ca e Pd } \\
\text { XE }\end{array}$ & Média & EPM \\
\hline $\mathrm{CMO}$ & 0,348 & 0,365 & 0,370 & 0,341 & 0,348 & 0,377 & 0,378 & 0,633 & 0,384 & 0,690 & 0,362 & 0,090 \\
\hline DMO & 0,074 & 0,074 & 0,075 & 0,074 & 0,074 & 0,075 & 0,076 & 0,980 & 0,899 & 0,871 & 0,074 & 0,011 \\
\hline F_MAX & 295,3 & 286,9 & 311,2 & 282,5 & 296,4 & 301,5 & 310,7 & 0,140 & 0,280 & 0,009 & 297,4 & 54,30 \\
\hline
\end{tabular}

$\mathrm{CMO}$, conteúdo mineral ósseo (g); DMO, densidade mineral óssea $\left(\mathrm{g} / \mathrm{cm}^{2}\right) ; \mathrm{F} \_\mathrm{MAX}$, força máxima $(\mathrm{N})$. 
Dilworth e Day (1965) afirmaram que a relação Ca:P da dieta está intimamente relacionada com a relação $\mathrm{Ca}: \mathrm{P}$ do osso, e quando esta relação da dieta não atende as exigências do animal, a relação no osso é afetada. Apesar da não diferença estatística, é possível observar resultados numericamente melhores para os parâmetros de resistência óssea nas dietas com inclusão de doses crescentes de fitase, portanto mais uma vez é possível observar a importância das reduções dos níveis de $\mathrm{Ca}$ e $\mathrm{Pd}$ sendo feitas na mesma proporção entre os dois minerais, esse fator pode ter contribuído para que não fossem apresentados problemas relacionados a resistência óssea no presente trabalho mesmo com a redução dos níveis de $\mathrm{Ca}$ e $\mathrm{Pd}$ nas dietas das aves.

Gráfico 2. Efeito dos níveis de Ca e Pd nas dietas e a adição de diferentes níveis de fitase sobre a força máxima $(\mathrm{N})$.

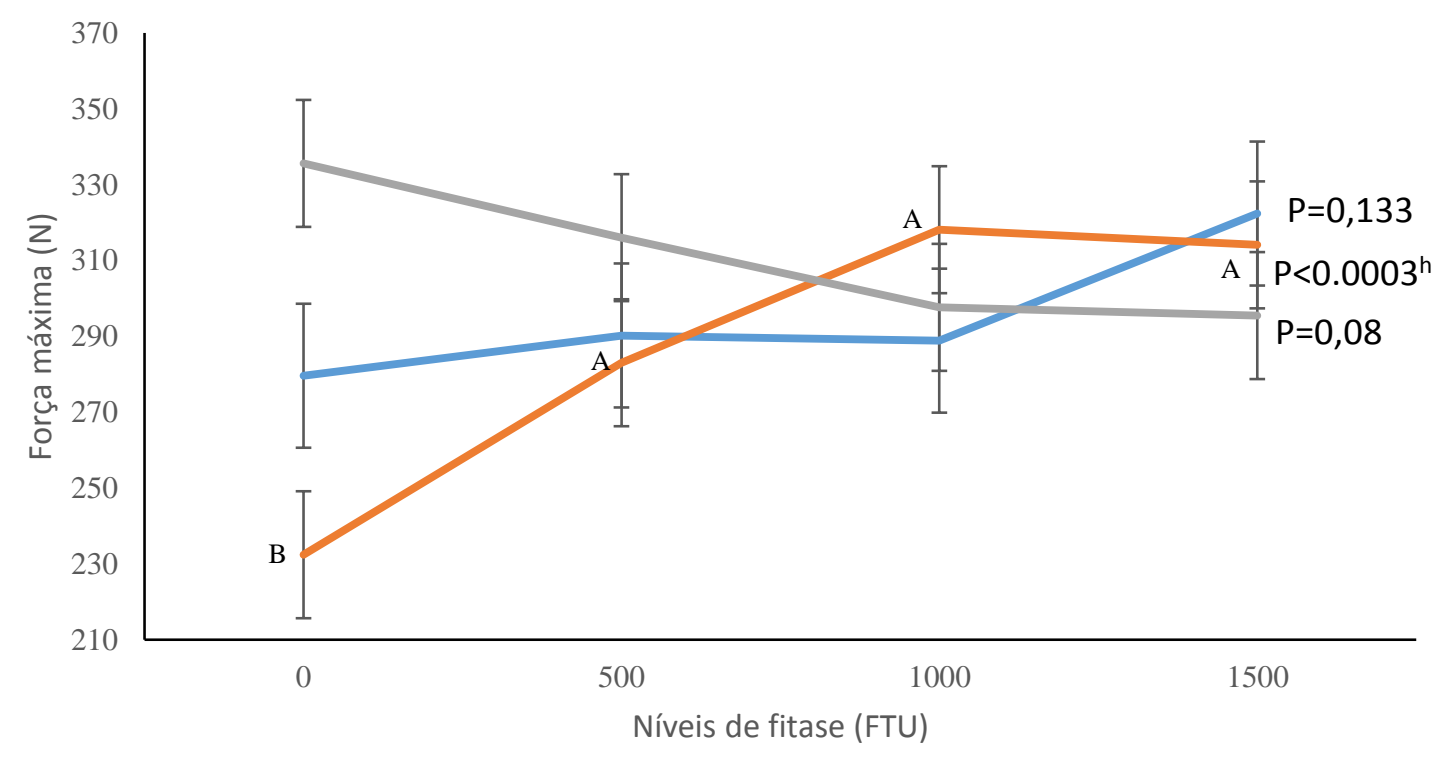

80\% (

${ }^{\mathrm{h}}$ Força Máxima $(\mathrm{N} ;$ TRAT $=90)=244,88( \pm 13,82)+0,05605( \pm 0,01478)$ enzima $(\mathrm{FTU})$.

Letras maiúsculas na mesma linha diferem estatisticamente pelo teste $F(0,05)$.

\section{CONCLUSÃO}

A redução de níveis de $\mathrm{Ca}$ e $\mathrm{Pd}$ em até $80 \%$ da recomendação pode ser considerada em dietas de frangos de corte sem causar efeitos adversos nas aves.

O uso da fitase microbiana em dietas de frangos de corte foi eficaz para os parâmetros de desempenho. A utilização de $1.500 \mathrm{FTU} / \mathrm{Kg}$ de ração da enzima fitase 
em dietas com $80 \%$ da recomendação dos níveis de Ca e Pd contribuiu para a melhora do ganho de peso na fase inicial.

É possível reduzir a recomendação de Ca e Pd das dietas, desde que seja feita a suplementação de fitase em até 1.000 FTU de fitase, sem que haja comprometimento da qualidade óssea. 


\section{REFERÊNCIAS BIBLIOGRÁFICAS}

ABPA. Associação Brasileira de Proteína Animal. Relatório Anual 2016. Disponível em:

http://abpa-br.com.br/setores/avicultura/publicacoes/relatorios-anuais. Acesso em: maio 2017.

ADEOLA, O.; OLUKSOSI, O.A.; JENDZA, J.A. et al. Response of growing pigs to Peniphora lycil e Escherichia coli derived phytase or varying ratios of calcium to total phosphorus. Journal of Animal Science, 2006. p.637- 644.

ADEOLA, O.; COWIESON, A. J. Board-Invited Review: Opportunities and challenges in using exogenous enzymes to improve nonruminant animal production. Journal of Animal Science, v.89, p.3189-3218, 2011.

AHMAD, T.; RASOOL, S.; SARWAR, M. et al. Effect of microbial phytase produced from a fungus Aspergillus Niger on bioavailability of phosphorus and calcium in broiler chikens. Animal Feed Science and Technology, v. 83, p. 103-114, 2000.

AHMAD, F.; RAHMAN, M.S.; AHMED, S.U.; MIAH, M.Y. Performance of broiler on phytase supplemented soybean meal based diet. International Journal of Poultry Science, v.3, n.4, p.266-271, 2004.

AHMAD, F.et al. Performance of broiler on phytase supplemented soybean meal based diet. International Journal of Poultry Science, v. 3, n. 4, p. 266-271, 2004.

AMOROSO, L. Respostas densitométricas, morfofisiológicas e desempenho de frangos de corte tratados com água filtrada e não filtrada. 91f. Tese (doutorado em Zootecnia) - Universidade Estadual Paulista, Jaboticabal, 2009.

ANGEL,R.; TAMIN, N.M. Phytate phosphorus hydrolysis as influenced by dietary calcium and micro minerals source in broiler diets. Journal of Agriculture and Food Chemistry, Easton, v.5, n. 16, p. 4687-4693, July 2003.

BAO, Y. M.; ROMERO, L. F.; COWIESON, A. J. Functional patterns of exogenous enzymes in different feed ingredients. World's Poultry Science Journal, v.69, p.759774, 2013.

BARADARAN N., SHAHIR M.H., et al. Effects of nonphytate phosphorus starter diet on subsequent growth performance and carcass characteristics of broiler chickens. Jour. Ani. Phys. Ani. Nutrit. 2013; 92 (1) 192-198.

BARREIRO, F. R. ; SAGULA, A. L. ; JUNQUEIRA, O. M. ; PEREIRA, G. T. ; BaraldiArtoni, S. M. . Densitometric and biochemical values of broiler tibias at different ages. Poultry Science. v. 88, p. 2644-2648, 2009.

BEAULIEU, A.D.; BEDFORD, M.R.; PATIENCE, J.F. The effect of phytase and dietary $\mathrm{Ca}: \mathrm{P}$ ratio on the excretion of total and soluble phosphorus by weaning pigs. Journal of Animal Science, v. 83, [Suppl.n.2], p.78, 2005. 
BEDFORD, M. R.; PARTRIDGE, G. G. Enzymes in farm animal nutrition. 407 p. Oxfordshire: UK, 2001.

BENEVIDES, C. M.J.; SOUZA, M. V.; SOUZA, R. D. B.; LOPES, M.V. Fatores antinutricionais em alimentos: revisão. R. Segurança Alimentar e Nutricional, Campinas, 18 (2): 67-79,2011.

BERTECHINI, A. G. Nutrição de monogástricos. Lavras: UFLA,2012. 255p.

BERTECHINI, A.G. Absorção e metabolismo de minerais em aves. IN: Curso de fisiologia da digestão e metabolismo dos nutrientes em aves, 2004, Jaboticabal. Anais... Jaboticabal: Unesp, 2004. CD-ROM.

BRENES, A.; VIVEROS, A.; ARIJA, I. et al. The effect of citric acid and microbial phytase on mineral utilization in broiler chicks. Animal Feed Science and Technology, v. 110, p.201-219, 2003.

BRUGALLI, I.; SILVA, D. J.; ALBINO, L. F. T. et al. Exigência de fósforo disponível e efeito da granulometria na biodisponibilidade de fósforo da farinha de carne e osso para pintos de corte. Revista Brasileira de Zootecnia, v. 28, n.6, p.1288-1296, 1999.

CAIRES, C. M.; FAGUNDES, N.S.; FERNANDES, E. A. et al. Enzimas na alimentação de frangos de corte. Revista Eletrônica Nutritime. v.5, n.1, p.491-497, 2008.

CAMDEN, B.J.; MOREL, P.C.H.; THOMAS, D.V. et al. Effectiveness of exogenous microbial phytase in improving the bioavailabilities of phosphorus and other nutrients in maize - soya-bean meal diets for broilers. Animal Science, v.73, n.2, p.289-297, 2001.

CEYLAN N., CANGIR S., CORDUK M., et al. The effects of phytase supplementation and dietary phosphorus level on performance and on tibia ash and phosphorus contents in broilers fed maize-soya based diets. Journ. Ani. Feed Scie. 2012; 21: 696-704.

CHEN X., MORAN Jr. ET. The withdrawal feed of broilers: Carcass responses to dietary phosphorus. J. Applied Poult. Res. 1995; 4: 69-82.

CHUNG T.K., RUTHERFURD S.M., THOMAS D.V., MOUGHAN P.J. Effect of two microbial phytases on mineral availability and retention and bone mineral density in lowphosphorus diets for broilers. Brist. Poult. Sci. 2013; 54 (3): 362-373.

COBB - VANTRESS BRASIL, LTDA. Manual de manejo de frangos de corte, 2012. Disponível em < http://www.cobb-vantress.com/languages/guidefiles/b5043b0f-792a448e-b4a1-4aff9a30e9eb_pt.pdf>. Acesso em: 26 de agosto de 2015.

CONTE, A.J. Valor nutritivo do farelo de arroz integral em rações para frangos de corte, suplementadas com fitase e xilanase. 2000, 164f. (Tese de Doutorado em Zootecnia) - Universidade Feral de Lavras, Lavras, 2000.

COSTA, F. G. P.; BRANDÃO, P. A.; BRANDÃO, J. S.; SILVA J. H. V. Efeito da enzima fitase nas rações de frangos de corte durante as fases pré inicial e inicial. Ciência Agrotécnica, Lavras, v. 31, n. 3, p. 865-870, maio/jun., 2007. 
DENBOW, D.M. et al. Soybeans transformed with a fungal phytase gene improve phosphorus availability for broilers. Poultry Science, Champaign, v.77, n.6, p.878-88, 1998.

DEMYR E, SEKERODLU A. The efficacy of phytase in broiler diets containing low phosphorus, calcium and crude protein. The Indian Journal of Animal Sciences, 2002.

DERSJANT-LI, Y., AWATI, A., SCHULZE, H., PARTTRIDGE, G. 2015. Phytase in nonruminant animal nutrition: a critical review on phytase activities in the gastrointestinal tract and influencing factors. J. Sci. Food Agr. 95, 878-896.

DILWORTH, B. C., Day, E. J. 1965. Effect of varying dietary calcium: phosphorus ratios on tíbia and fêmur composition of the chick. Pout. Sci. 44, 1474-1479.

EDWARDS Jr., H. M.,. Dietary 1, 25-Dihydroxycho1ecalciferol supplementation increases natural phytate phosphorus utilization in chickens. Journal of Nutrition, p.567-577., 1993

FUKAYAMA, E. H.; SAKOMURA, N. K.; DOURADO, L. R. B.; NEME, R.; FERNANDES, J. B. K.; MARCATO, S. M. Efeito da suplementação de fitase sobre o desempenho e a digestibilidade dos nutrientes em frangos de corte. R. Bras. Zootec., v.37, n.4, p.629635, 2008.

GEORGIEVSKII, V.I. Mineral Nutrition of animal: studies in the agricultural and food Science. London: Butterworths, 1982. 474p.

GOMEZ ALONSO C.; RODRÍGUEZ GARCÍA, M.; CANNATA, J.B. Metabolismo del cálcio, del fósforo y del magnesio. Sección I: Estructura y Regulación Del.

GOMIDE, E.M.; RODRIGUES, P.B.; BERTECHINI, A.G. et al. Rações com níveis reduzidos de proteína bruta, cálcio e fósforo com fitase e aminoácidos para frangos de corte. Revista Brasileira de Zootecnia, v.40, n.11, p.2405-2414, 2011.

JHONSTON, S.L.; SOUTHERN, L.L. The effect of varying mix uniformity (simulated) of phytase on growth performance, mineral retention and bone mineralization in chicks. Poultry Science, Champaign, v.79, n.10, p.1485-1490, 2000.

KEBREAB, E.; HANSEN, A. V.; STRATHE, A. B. Animal production for efficient phosphate utilization: from optimized feed to high efficiency livestock. Current Opinion in Biotechnology, v.23, p.872-877, 2012.

KESHAVARZ, K. Por que es necessario emplear la fitasa em la dieta de las ponedoras? Industria Avicola, Illinois, v.46, n. 10, p. 13-14, Oct. 1999.

KLASING, K.C. Comparative avian nutrition. New York: Cab International, 1998. 350p. 
KORNEGAY E.T., DENBOW D. M. Supplemental microbial phytase improves zinc utilization in broilers. Poult. Sci. 1996; 75: 540-546.

LAURENTIZ, A. C.; JUNQUEIRA, O. M.; FILARDI, R. S.; ASSUENA, V.; CASARTELLI, E. M.; COSTA, R. Efeito da adição da enzima fitase em rações para frangos de corte com redução dos níveis de fósforo nas diferentes fases de criação. Ciência Animal Brasileira, v. 8, n. 2, p. 207-216, abr./jun. 2007.

LEESON, S. Enzimas para aves. In: SIMPÓSIO INTERNACIONAL SOBRE NUTRIÇÃO DE AVES, 1., 1999, Campinas. Anais... Campinas: FACTA, 1999. P. 173-185.

LIMA, F. R. Quantidade e qualidade do fósforo na nutrição mineral. Avicultura: ciências \& tecnologia, Campinas, n. 14, p. 20-25, 1995.

LIU, N. et al. Effect of diet containing phytate and phytase on the activity and messenger ribonucleic acid expression of carbohydrase and transporter in chickens. Journal of Animal Science, v.86, p.3432-3439, 2008a.

Lopes, R.C.S.O. 2009. Avaliação de fêmures de frangos de corte alimentados com farelo de resíduo de manga. Dissertação (Mestrado em Bioquímica Agrícola). UFV. Viçosa-MG

MACARI, M.; FURLAN, R.L.; GONZALES, L. Fisiologia aviária aplicada a frangos de corte. Jaboticabal, FUNEP/UNESP, 2002. 375p.

MANANGI, M.K.; COON, C.K., Phytate phosphorus hidrolysis in broilers in response to dietary phytase, calcium and phosphorus concentrations. Poultry Science, Champaign, v. 87, n. 8, p. 1577-1586, Aug. 2008.

MAYNARD, L.A.; LOOSLY, J.K.; HINTZ, H.F. et al. Nutrição animal. 3.ed., Rio de Janeiro:Freita Bastos, 1984. 736 p.

McDONALD, P.; EDWARDS, R.A.; GREENHALGH, J.F.D. Nutrición Animal. Zaragoza, Editorial Acribia S.A., 1993. 571p.

McDOWELL, L.R. Minerals in Animal and Human Nutrition. New York: Academic Press, 1992. 523p.

McDOWELL, L.R. Minerals in Animal and Human Nutrition. 2. ed. Netherlands: Elsevier Science, 2003. 644 p.

McNAUGHTON, J. L; DEATON. Effect of calcium source and particle on calcium utilization. Poultry Science, v.59, n.7, p.1568, 1981. Suplemento. (Abstracts).

MORRIS, E.R. Phytate and mineral biovailability. In: GRAF, E. Phytate Chesmistry and Application, Minneapolis: Pilatus. 1986. P. 57-76.

MUNIZ, E.B.; ARRUDA, A.M.V.; FASSANI, E.J. et al. Redução do nível de cálcio dietético para frangos de corte na fase inicial de crescimento. Rev. Caatinga, v.20, p.58-69, 2007. 
NAVES, L.P. Metodologias para quantificar fitato e uso de fitases em rações para frangos de corte. 2012. 152f. Dissertação (Doutorado em Zootecnia) - Universidade Federal de Lavras, Minas Gerais, 2012.

NELSON, T.S., MILLES, R.D. Effect of calcium and phosphorus on energy utilization by chicks. Poultry Science, v. 51, p. 1536-1540, 1972.

NUNES, I.J. Nutrição Animal Básica. Minas Gerais: Universidade Federal de Minas Gerais, 1998. 387p.

OLIVEIRA, M. C.; GRAVENA, R. A.; MARQUES, R. H.; GUANDOLINI, G. C.; MORAES, V. M. B. Utilização de nutrientes em frangos alimentados com dietas suplementadas com fitase e níveis reduzidos de fósforo não-fítico. Arq. Bras. Med. Vet. Zootec., v.60, n.2, p.436-441, 2008.

OLIVEIRA, M.C; MARQUES, R.H.; GRAVENA, R.A. et al. Fitase em dietas com níveis de fósforo não fítico para frangos de corte. Revista Biotermas, v.22, n.4, p.169-176, 2009.

PALLAUF, J.; RIMBACH, G. Recent results on phytic acid and phytase. In: Proceedings of Forum Animal Nutrition, Anais, BASF, 1995

PENZ JR, A.M. Enzimas em rações para aves e suínos. In: Reunião Anual da Sociedades Brasileiras de Zootecnia, 1998. Botucatu. Anais... Botucatu, Editora São Paulo, 1998. p. 165-178.

PINHEIRO, S. R. F. Níveis de fósforo, de cálcio e de cloreto de sódio para aves de linhagens de crescimento lento criadas em sistema semi-confinado. Tese Doutorado, UNESP Jaboticabal, 2009

PIZZOLANTE, C. C.; TEIXEIRA, A. S.; SANTOS, C. D. Utilização da fitase na alimentação de frangos de corte: desempenho. In: CONFERÊNCIA APINCO 2000 DE CIÊNCIA E TECNOLOGIA AVÍCOLAS, 2000, Campinas. Anais... Campinas: FACTA, p. 45, 2002.

POINTLLART, A., FONTAINE, N and THOMASSET, M. Phytate phosphorus utilization and intestinal phosphatases in pigs fed low phosphorus: wheat or corn diets. Nutr. Rep. Int., v.29, p.473-483, 1984.

POWELL, S.; JOHNSTON, L.; GASTON, L. L. et al.; The Effect of Dietary Phosphorus Level and Phytase Supplementation on Growth Performance, Bone-Breaking Strength, and Litter Phosphorus Concentration in Broilers. Poult Sci 2008; 87 (5): 949-957. doi: 10.3382/ps.2007-00291

QUIAN, H.; H..; KORNEGAY, E.T.; DENBOW, D.M. Utilization of phytate phosphorus and calcium as influenced by microbial phytase, cholecalciferol, and the calcium: total phosphorus ratio in broiler diets. Poultry Science, Champaign, v.76, n. 1, p. 37-46, Jun. 1997. 
REIDE, L.; WEBER, C.W. Calcium availability and trace minerals composition of feed grade calcium supplements. Poultry Science, v.55, p.695-712, 1972.

RICHARDS, J.D. et al. Trace mineral nutrition in poultry and swine. Asian-Australasian Journal Animal Science, Seoul, v.23, n. 11, p. 1527-1534, 2010.

ROSOL, T.J.; CAPEN, C.C. Calcium-regulating hormones and diseases of abnormal mineral (calcium, phosphorus, magnesium) metabolism. In: Kaneko, J.J.; Harvey, J.W.; BRUSS, M.L. (eds). Clinical Biochemistry of domestic animals. Fifth edition. San Diego: Academic Press, 1997. p.619-702. 1997.

ROSTAGNO, H. S. Tabelas brasileiras para aves e suínos: composição de alimentos e exigências nutricionais. Viçosa: UFV, 2011.

SAKOMURA, N.Z.; SILVA, J. H. V.; COSTA, F. G. P et al. Nutrição de não ruminantes. Jaboticabal, FUNEP, 2014.

SANTOS, L.M. Níveis de cálcio e fósforo disponível para frangos de corte recebendo rações com fitase em diferentes fases de criação. Universidade Federal de Lavras, 2008. 105p.:il.

SANTOS T.T. Phytate: anti-nutrient for poultry and swine. Feedstuffs. 2012; 84: 1-3.

SCHOULTEN, N.A.; TEIXEIRA, A.S.; BERTECHINI, A.G.; et al. Efeito dos níveis de cálcio sobre a absorção de minerais em dietas iniciais para frangos de corte suplementadas com fitase. Ciênc. Agrotec., Lavras. V.26, n.6, p. 1313-1321, nov./dez., 2002.

SEBASTIAN, S.; TOUCHBURN, S. P.; CHAVEZ, E. R. Efficacy of supplemental microbial phytase at different dietary calcium levels on growth performance and mineral utilization on broiler chickens. Poultry Science, London, v. 75, p. 1516- 1522, 1996.

SEBASTIAN, S.; TOUCHBURN, S.P.; CHAVEZ, E.R. et al. Apparent digestibility of protein and amino acids in broiler chickens fed a corn-soybean diet supplemented with microbial phytase. Poultry Science, v.76, n.12, p.1760-1769, 1997.

SELLE, P. H. et al. Phytase Supplementation of Sorghum-Based Broiler Diets with Reduced Phosphorus Levels. ANNUAL AUSTRALIAN POULTRY SCIENCE SYMPOSIUM, 21, Sydney, New South Wales. Proceedings... Sydney: The Poultry Research Foundation and The World's Poultry Science Association, 2012. p.70-73.

SELLE, P.H.; RAVIDRAN, V.; Microbial phytase in poultry nutrition. Animal Feed Science and Technology, v.135, p. 1-41, 2007.

SHOENER, F.J., HOPPE, P.P., SCWARZ, G. WESCHE, H. Comparison of microbial phytase and inorganic phosphate in male chickens ñ the influence on performance data, mineral retention and dietary calcium. J. Anim. Phys. Nutrit., v.69, p.235-244, 1993.

SHIRLEY, R.B.; EDWARDS JR, H.M. Graded levels of phytase past industry standards improves broiler performance. Poult. Sci., Champaign, v.8, p.671-680, 2003. 
SIMONS, P. C. M.; VERSTEEGH, H. A. J. Improvement of phosphorus availability by microbial phytase in broilers and pigs. British Journal of Nutrition, London, v. 64, n.3, p. 525-540, Nov. 1990.

SILVA, Y. L.; RODRIGUES, P. B.; FREITAS, R. T. F.; ZANGERONIMO, M. G.; FIALHO, $E$. T. Níveis de proteína e fósforo em rações com fitase para frangos de corte, na fase de 14 a 21 dias de idade. Valores energéticos e digestibilidade de nutrientes. R. Bras. Zootec., v.37, n.3, p.469-477, 2008.

SILVA, Y.L.; RODRIGUES, P.B.; ZANGERONIMO, M.G. et al. Redução de proteína e fósforo em dietas com fitase para frangos de corte dos 22 a 42 dias de idade. Arquivo Brasileiro de Medicina Veterinária e Zootecnia, v.64, n.1, p.127-136, 2012.

SILVA, A.R.Z.; SOCCOL, C.R.; GERN, J.C.; FERRER, P.P. Produção de Fitase por Fermentação no Estado Sólido utilizando Biorresíduos Agrícolas para a Aplicação como Aditivo na Alimentação Animal. In: www.enq.ufsc.br/eventos/sinaferm/trabalhos_completos/t338.doc, acessado em 04 de dezembro de 2016.

SMITH, O. B.; KABAJA, E. Effect of high dietary calcium and wide calcium/ phospohorus rations in broiler diets. Poltry Science, v.64, p.1713-1720, 1984.

UNDERWOOD, E. J., SUTTLR, N. F. The Mineral Nutrition of Livestock. 3 ed. Wallingford, CABI Publishing, 1999. 614 p.

VATS, P.; BANERJEE, U.C. Production studies and catalytic properties of phytases (myo-inositolhexakisphophate phosphohydrolases): an overview. Enzyme and Microbial Technology, New York, v.35, n.1, p. 3-14, July 2004.

VIVEROS, A.; BRENES, A.; ARIJA, I. et al. Effects of microbial phytase supplementation on mineral utilization and serum enzyme activities in broiler chicks fed different levels of phosphorus. Poultry Science, v.81, n.8, p.1172-1183, 2002.

WALDROUP, P.W. Bioassays remain necessary to estimate phosphorus, calcium bioavailability. Feedstuffs, v.68, p.13-20, 1996.

WALDROUP, P.W., AMMERMAN, C.B., HARMS, R.H. Calcium and phosphorus requirements of finishing broilers using phosphorus sources of low and high availability. Poultry Science, v.42, p.752-757, 1963.

WALKER C.L., SANTOS T.S., BEDFORD, M.R. Influence of superdoses of a microbial phytase on growth performance, tibia ash, and gizzard phytate and inositol in young broilers. Poult. Scie. 2014; 93 (5): 1172-1177.

WEGLARZ, M. P.; ANGEL, R. Calcium and phosphorus metabolism in broilers: effect of homeostatic mechanism on calcium and phosphorus digestibility. Journal of Applied Poultry Research, Osford, v. 22, n. 3, p. 609-621, 2013. 
ZANELLA, I.; SAKOMURA, N.K.; SILVERSIDES, F.G. et al. Effect of enzyme supplementation of broiler diets based on corn and soybeans. Poultry Science, v.78, p.561-568, 1999. 